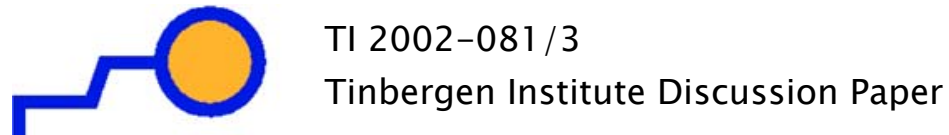 \\ Comparative Advantage, Relative Wages, and the Accumulation of Human Capital
}

Final version

C.N. Teulings

University of Amsterdam. 


\section{Tinbergen Institute}

The Tinbergen Institute is the institute for economic research of the Erasmus Universiteit Rotterdam, Universiteit van Amsterdam, and Vrije Universiteit Amsterdam.

Tinbergen Institute Amsterdam

Roetersstraat 31

1018 WB Amsterdam

The Netherlands

Tel.: $\quad+31(0) 205513500$

Fax: $\quad+31(0) 205513555$

Tinbergen Institute Rotterdam

Burg. Oudlaan 50

3062 PA Rotterdam

The Netherlands

Tel.: $\quad+31(0) 104088900$

Fax: $\quad+31(0) 104089031$

Please send questions and/or remarks of nonscientific nature to driessen@tinbergen.nl.

Most TI discussion papers can be downloaded at http://www.tinbergen.nl. 


\title{
Comparative Advantage, Relative Wages, and the Accumulation of Human Capital
}

\author{
Coen N. Teulings
}

University of Amsterdam

\begin{abstract}
I apply Ricardo's principle of comparative advantage to a theory of factor substitutability in a model with a continuum of worker and job types. Highly skilled workers have a comparative advantage in complex jobs. The model satisfies the distance-dependent elasticity of substitution (DIDES) characteristic: substitutability between types declines with their skill distance. I analyze changes in relative wages due to human capital accumulation. The concept of a complexity dispersion parameter or compression elasticity is introduced. Empirical studies suggest its value to be equal to two: a 1 percent increase in the stock of human capital reduces the Mincerian return by 2 percent.
\end{abstract}

\section{Introduction}

The substitutability between worker types has been an important issue in economics for a long time. The standard approach has been rather eclectic. Workers were categorized in a number of types, and a standard "black box" production function has been applied, for example, a constant elasticity of substitution (CES) function or one of the more flexible functional forms that have been proposed by Diewert (1971). This paper follows a new approach on this issue. The theory of substitution between worker types is linked to another strand in the literature, that of the assignment models (see Tinbergen 1956; Rosen 1974; Sattinger 1975;

I thank the participants of seminars at the Tinbergen Institute in Amsterdam, University College London, and at the Society of Labor Economists/European Association of Labour Economists meeting in Milan; Lex Borghans, Pieter Gautier, Joe Kabowski, David Margolis, Costas Meghir, Sebastian Perez Duarte, Aico van Vuuren, Fernando Alvarez as the editor, and an anonymous referee for comments; and Vladimir Protassov for assistance with the analysis of differential equations.

[Journal of Political Economy, 2005, vol. 113, no. 2]

(C) 2005 by The University of Chicago. All rights reserved. 0022-3808/2005/11302-0006 $\$ 10.00$ 
Heckman and Sedlacek 1985; Teulings 1995). In these models, both labor supply and demand are heterogeneous. The question is how workers are assigned to tasks in market equilibrium. The wages for various worker types follow as a by-product of the optimal assignment. The natural approach is then to do comparative statics: How do shifts in the distribution of worker types affect both the assignment of workers to tasks and the wages for various worker types? Comparative statics in assignment models therefore answers the same question as the theory of substitution: How do shifts in the relative supply of worker types affect their relative wages?

The analysis in this paper shows that this approach yields a more realistic pattern of substitutability between worker types than most standard black box production functions. The production technology in the assignment model is based on a continuum of worker and task types (see Teulings 1995). Workers are characterized by a single index, their skill level $s$. Similarly, tasks are characterized by another index, their level of complexity $c$. The driving force in the analysis is the Ricardian concept of comparative advantage: better-skilled workers have a comparative advantage in complex jobs. The analysis shows that this assumption leads to what I call a distance-dependent elasticity of substitution (DIDES) structure: the smaller the "distance" between the skill level of two worker types, the better substitutes these worker types are. This structure contrasts sharply with, for example, the structure implied by Dixit and Stiglitz's (1977) "love for variety" CES production function. There, the increase in the supply of one type reduces its own wage and raises the wages for all other types by the same amount.

The model is applied to the analysis of the general equilibrium effects of a general increase in human capital on relative wages. It turns out that general equilibrium effects can be decomposed into two parts, composition and extension effects. For the sake of argument, suppose that we provide training to 100 workers of skill type $s$, which raises their skill level to $s+\Delta$. Suppose that the wage for type $s+\Delta$ is 1 percent higher than that for type $s$. Since we are in a Walrasian world, this 1 percent higher wage implies a 1 percent increase in the marginal productivity of these workers, so that 99 of the trained workers can now do the job of the 100 untrained workers. The composition effect of the additional human capital on relative wages arises because we remove 100 workers from skill group $s$ (the "source" type) and add the "production equivalence" of 99 workers to skill group $s+\Delta$ (the "destination" type), leaving the total production capacity of skill groups $s$ and $s+\Delta$ together unchanged. The extension effect of the additional human capital is the 100 th worker that we add to skill group $s+\Delta$. This measures the increase in production capacity.

The composition effect leaves unchanged the production capacity of skill 
types below $s$ or above $s+\Delta$ relative to the capacity between $s$ and $s+\Delta$. These workers are assigned to exactly the same $c$ type of task after and before. Nevertheless, I prove the remarkable result that the wages for skill types below $s$ are raised relative to the wages for skill types higher than $s+\Delta$. Hence, composition effects always compress the wage distribution.

The extension effect captures the effect of the net increase in production capacity of types $s$ and $s+\Delta$ together on relative wages: the 100th worker that is added to group $s+\Delta$. The extra capacity in the region between $s$ and $s+\Delta$ raises productivity there and hence reduces wages in that region. Slightly higher- and slightly lower-skilled workers are the best substitutes for these workers. Hence, their wages decline too, but by less than those of types $s$ and $s+\Delta$, and so on. The remarkable feature of extension effects on relative wages is that they cancel if all skill types get the same relative increase in the value of their human capital. The intuition for this result is simple: since all workers get the same increase, the extension effect is equivalent to a proportional increase in labor supply for all skill types. With constant returns to scale, a proportional increase in supply of all inputs raises output but does not affect input prices. Since extension effects on relative wages cancel, composition effects are all that matters in that case. Since composition effects compress the wage distribution, an equiproportional increase in the human capital of all workers will compress the wage distribution. Teulings and van Rens (2002) provide support for this idea, using panel data over the postwar period for some 100 countries.

This analysis has important implications, both for the measurement of the returns to training programs and for economic policy. Heckman, Lochner, and Taber $(1998 a, 1998 b)$ have argued that standard methods for evaluating training programs are biased, since they ignore general equilibrium effects. My analysis confirms their conclusion and provides a general way to characterize this effect. The results enable a better targeting of training programs to the relief of the low-skilled. Programs that are geared to somewhat better-skilled workers can be more effective, since less skilled workers benefit from the general equilibrium effects.

The particular nonlinearities of my model can resolve a puzzle regarding the increase in wage inequality in the United States during the 1980s. While the return to human capital has gone up for all wage levels more or less by the same amount, changes in the supply of and demand for skill differ greatly between skill levels. Juhn, Murphy, and Pierce (1993) have shown that the demand for skill has gone up in the highest percentiles of the skill distribution only. This combination of an increase in demand only at the top and an across-the-board increase in the return to human capital has been hard to explain. However, next to the increase in demand at the top, the fall in minimum wages during the period is 
likely to have produced an increase in skill supply at the lowest percentile of the skill distribution (people who were previously without a job because of the minimum wage). Teulings (2003) has shown that the fall in minimum wages indeed had large effects on relative wages, consistent with the predictions of the DIDES model. Also, in this model, the combination of an increase in the demand for skill at the top and an increase in supply at the bottom yields the equiproportional increase in the return to human capital at all skill levels that are observed empirically.

A crucial role in the analysis is played by the locus of log wages in market equilibrium, $w(s)$, and in particular by its first and second derivatives. The complexity index $c$ is defined such that it measures the $\log$ productivity gain of an additional unit of skill. Hence, the higher $c$, the more the level of skill matters, which is the definition of comparative advantage. In equilibrium, a type $c$ firm hires that worker type for which the first derivative $w^{\prime}(s)$ is equal to its $c$ : the marginal relative productivity gain of an additional unit of skill, $c$, is equal to the marginal relative increase in wage cost, $w^{\prime}(s)$. This relation provides a direct link between the assignment of workers to tasks and the wages for worker types. Changes in the one feed back into the other, and vice versa. Hence, the second derivative $w^{\prime \prime}(s)$ measures the sensitivity of the equilibrium assignment to small shifts in wages. When the second derivative is high, shifts in wages have small effects on the equilibrium assignment. Hence, worker types are bad substitutes. The crucial role of the magnitude of this second derivative has a direct analogue in the standard approach to the substitutability between types. There, elasticities of substitution are derived from the second derivative of the cost function. Here, $w^{\prime \prime}(s)$ takes over that role.

I introduce the concept of the complexity dispersion parameter. HicksAllen elasticities of complementarity (Hicks-Allen elasticities of substitution will be shown not to be a useful concept in the context of a DIDES structure) are fully determined by the distribution of wageswhich can be observed directly from the data-and this complexity dispersion parameter. It measures the degree of comparative advantage. Alternatively, it can be interpreted as a measure of the cost for a firm of not hiring the optimal worker type: the higher the complexity dispersion parameter, the higher the relative cost increase of hiring a too highly or a too lowly skilled worker. The great advantage of the complexity dispersion parameter is that it is free of dimension, so that it can be meaningfully compared across countries, across time, and across various points in the wage distribution.

I provide a simple workhorse model in which both the supply of skill and the demand for complexity are assumed to be distributed normally. When the standard deviations of both distributions are equal, this workhorse model yields a convenient closed-form solution for the wage dis- 
tribution and the complexity dispersion parameter. Up to now, Tinbergen's (1956) paper was the only known closed-form solution in this class of models. Furthermore, I provide a Taylor expansion of the equilibrium for the case in which the standard deviations of skill supply and complexity demand are different. A rise in the mean of the skill distribution can be interpreted as human capital accumulation, and a rise in the mean of the complexity distribution as skill-biased technical change. Both have exactly opposite effects on relative wages. This provides a convenient parameterization of Tinbergen's race between education and technology.

When the standard deviations of skill supply and complexity demand are equal, the workhorse model provides an additional interpretation of the complexity dispersion parameters as being the compression elasticity: the percentage reduction in the Mincerian rate of return to human capital per percentage increase in the value of the stock of human capital. I provide a simple transformation rule of Katz and Murphy's (1992) much-cited elasticity of substitution between low- and highskilled workers of 1.4 and the complexity dispersion parameter. According to this rule, the complexity dispersion parameter is about two. Under the assumption of an initial rate of return to a year of schooling of 10 percent, an increase of the average level of education of the workforce by one year reduces this rate of return by $2 \times 10$ percent $=$ 20 percent, that is, from 10 percent to 8 percent.

The paper is organized as follows. Section II sets out the structure of the economy and the cost function that goes with it. Section III deals with the derivation of the elasticities of substitution and complementarity. In Section IV, the complexity dispersion parameter is introduced, and the framework is applied to a general increase in human capital. Section V presents my workhorse model. Section VI presents conclusions.

\section{The Structure of the Economy}

\section{A. Assumptions}

Consider an economy producing a composite commodity by means of the input of an infinite number of different tasks. Production does not require other inputs. Task types are indexed by a continuous index $c \in\left[c^{-}, c^{+}\right], c^{-} \geq 0$. The index $c$ will be referred to as the level of task complexity. Each firm produces a single task. The markets for tasks are perfectly competitive, and there is free entry of firms. A zero-profit condition for firms therefore applies. The relation between the input of tasks and the output of the composite commodity is given by a continuous-type Leontief technology. Let $\exp [\delta(c)]$ be the required input 
of type $c$ per unit of output of the composite commodity. Throughout the paper, Greek characters denote exogenous parameters or functions. Furthermore, lowercase letters denote the logs of the corresponding uppercase letters. Then the production function of the composite commodity is

$$
Y=\min _{c} \exp [-\delta(c)+x(c)]
$$

where $Y$ is the output of the composite commodity and $x(c)$ is the log input of task type $c$. The log cost function per unit of output for this Leontief technology is

$$
p=\ln \int_{c^{-}}^{c^{+}} \exp [\delta(c)+\tilde{p}(c)] d c,
$$

where $p$ denotes the $\log$ price per unit of output, and $\tilde{p}(c)$ is the $\log$ price of a type $c$ task (the tilde is used to distinguish task prices from the price of the composite commodity). A type $c$ task can be produced by workers with various skill levels, which differ by their productivity. There are $I$ types of workers, each type endowed with a skill level $s_{i}$, $i=1, \ldots, I$. The labor markets for worker types are perfectly competitive. Define $s_{0} \equiv s^{-}$, and let $s_{i}=s_{i-1}+\Delta s(I)$, where $\Delta s(I)$ is a constant satisfying $\Delta s(I)=\left(s^{+}-s^{-}\right) / I$. Hence $s_{I}=s^{+}$. The domain of the skill variable is therefore divided into a number of intervals of equal width and $s$ jumps stepwise. The case of continuous variation in the skill level $s$ will be approximated by considering the sequence of economies, $I=I_{0}, I_{0}+1, I_{0}+2, \ldots$, keeping all other parameters of the economy fixed. Hence, in the limit, $I \rightarrow \infty$ or, equivalently, $\Delta s(I) \rightarrow 0$. In this limiting case, this economy is equivalent to the model considered in Teulings (1995). For the sake of notational convenience, the argument of $\Delta s$ is suppressed in what follows and I write $\lim _{\Delta s \rightarrow 0}$ when referring to $\lim _{I \rightarrow \infty}$.

\section{Assumption A.}

1. The output of a type $c$ task produced by a type $s_{i}$ worker is $f\left(s_{i}, c\right) \equiv \exp \left(s_{i} c\right)$.

2. The labor supply of type $s_{i}$ is equal to $N_{i} \equiv \exp \left[\chi\left(s_{i}\right)\right] \Delta s>0$.

3. The functions $\chi(s)$ and $\delta(c)$ are bounded and once differentiable.

The specification of output per worker type $s_{i}$ in a type $c$ task captures the notions of absolute and comparative advantage (Teulings 1995, 285). Absolute advantage implies that an additional unit of skill yields higher output, irrespective of the task type $c$ to which a worker is assigned $\left(f_{1}(\cdot)>0\right)$. Comparative advantage implies that the higher task complexity $c$ is, the higher the relative productivity gain of the marginal unit 
of skill $\Delta s\left(f_{12}(\cdot) f(\cdot)>f_{1}(\cdot) f_{2}(\cdot)\right.$ or, equivalently, $f(\cdot)$ is log supermodular). In part 2 of assumption $\mathrm{A}$, the right-hand side is multiplied by $\Delta s$ such that the limit of $\Delta s \rightarrow 0$ of total employment $\sum_{i} N_{i}$ converges to a constant. The functions $\chi(s)$ and $\delta(c)$ can be interpreted as the log density functions of skill supply and complexity demand, respectively.

\section{B. Market Equilibrium and the Cost Function}

Consider a market equilibrium in this economy. This equilibrium is characterized by an aggregate level of output $Y$, an assignment of worker types $s_{i}$ to task types $c$, and a vector of $\log$ wages $w_{i}$ for each worker such that (i) all worker types $i$ are fully engaged in the production of at least one $c$ type, (ii) the markets for all $c$ types clear, and (iii) each type $c$ firm employs that worker type $i$ that minimizes production cost per unit of output. Condition iii implies that a type $c$ firm chooses its worker type $i$ so as to minimize the cost per unit of task $c$, $\exp \left(w_{i}-s_{i} c\right)$. Let $c_{i}$ be a firm type that is indifferent between employing worker type $i$ and type $i-1$ and weakly prefers these types above others. Hence, $c_{i}$ is defined implicitly so as to satisfy

$$
\begin{aligned}
s_{i} c_{i}-w_{i} & \equiv s_{i-1} c_{i}-w_{i-1} \geq s_{j} c_{i}-w_{j} \quad \forall j \\
& \Rightarrow c_{i} \Delta s=\Delta w_{i},
\end{aligned}
$$

where $\Delta$ is the first-difference operator. Furthermore, it is convenient to define $w(s)$ as the locus of wages that applies in the limiting case of continuous variation in $s$ :

$$
w\left(s_{i}\right) \equiv \lim _{\Delta s \rightarrow 0} w_{i} .
$$

A full characterization of the equilibrium is not required for the purpose of this paper (see Teulings [1995] for that). Proposition 1 establishes the characteristics of $c_{i}$ and $w(s)$ that we do need for the subsequent analysis.

\section{Proposition 1.}

1. Firm type $c_{i}$ exists for all $i$;

2. $\Delta c_{i}>0$ for all $i=2, I$;

3. $\Delta w_{i}>0$ for all $i=2, I$;

4. $\quad \Delta^{2} w_{i}>0$ for all $i=3, I$;

5. $w(\cdot)$ is twice differentiable; and

6. $w^{\prime}\left(s^{-}\right)=c^{-}$and $w^{\prime}\left(s^{+}\right)=c^{+}$.

The proof is relegated to Appendix A. Parts 1 and 2 imply that consecutive skill types $s_{i-1}$ and $s_{i}$ are employed in consecutive, connected but nonoverlapping intervals of the task type index $c$, where higher skill 
types are employed in the more complex tasks (comparative advantage). Hence, there exists a unique skill type $s_{i}$ that minimizes the cost per unit of output of type $c$, exp $\left(w_{i}-s_{i} c\right)$ for each task type $c$, except for the borderline $c$ types $c_{i}$. In the limiting case of $\Delta s \rightarrow 0$, this translates into a one-to-one correspondence between $s_{i}$ and $c$. Part 3 states that better-skilled workers earn higher wages because of absolute advantage. Part 4 is a direct implication of part 2. In fact, the condition $c_{i} \Delta s=$ $\Delta w_{i}$ in equation (2) is the first-order condition for cost minimization of firm type $c_{i}$, whereas the condition $\Delta^{2} w_{i}>0$ in part 4 is the second-order condition. The first-order condition stipulates that the relative productivity gain of employing type $i$ instead of type $i-1, c_{i} \Delta s$, should be equal to the relative increase in the wage bill, $\Delta w_{i}$. Part 5 implies that

$$
\begin{gathered}
\lim _{\Delta s \rightarrow 0} \frac{\Delta w_{i}}{\Delta s}=\lim _{\Delta s \rightarrow 0} c_{i}=w^{\prime}\left(s_{i}\right)>0, \\
\lim _{\Delta s \rightarrow 0} \frac{\Delta^{2} w_{i}}{(\Delta s)^{2}}=\lim _{\Delta s \rightarrow 0} \frac{\Delta c_{i+1}}{\Delta s}=w^{\prime \prime}\left(s_{i}\right)>0 .
\end{gathered}
$$

For the derivation of the cost function of the composite commodity of this economy, it is useful to write $c_{i}$ as a function of $w_{i}$ and $w_{i-1}$ :

$$
\begin{gathered}
c_{i}\left(w_{i-1}, w_{i}\right) \equiv \frac{w_{i}-w_{i-1}}{\Delta s} \quad \forall i=2, I, \\
c_{1} \equiv c^{-}, \quad c_{I+1} \equiv c^{+} .
\end{gathered}
$$

By the zero-profit condition for firms, the task prices for all tasks satisfy

$$
\tilde{p}(c)=w_{i}-s_{i} c \quad \forall c \in\left[c_{i}, c_{i+1}\right] .
$$

Substituting these relations in equation (1) yields the log cost per unit of the composite commodity $p(\underline{w})$ as a function of a vector of log wages for all worker types:

$$
p(\underline{w})=\ln \sum_{i=1}^{I} \int_{c_{i}\left(w_{i-1}, w_{i}\right)}^{c_{i+1}\left(w_{i}, w_{i+1}\right)} \exp \left[\delta(c)+w_{i}-s_{i} c\right] d c,
$$

where $\underline{w} \equiv\left\{w_{i}\right\}$ denotes the vector of input prices (throughout the paper, vectors are underlined). The wages of worker types enter along two channels. First, they enter in the integrand: production cost per task type, with the assignment of workers taken as given. An increase in $w_{i}$ raises the production cost for the task types $c \in\left[c_{i}, c_{i+1}\right]$ that employ type $i$. Second, they enter via the upper and lower bounds of the integration intervals. Each interval delimits the set of tasks $c$ that employ a particular worker type $i$. An increase in $w_{i}$ induces firms close to the borderlines of the interval $\left[c_{i}, c_{i+1}\right]$ to shift their demand to neighboring 
skill types $i-1$ and $i+1$, respectively: $c_{i}$ shifts upward and $c_{i+1}$ shifts downward. The cost function (5) is the starting point of the analysis of elasticities of substitution and complementarity in the next section.

\section{Derivation of the Elasticities}

Suppose that we increase the labor supply of a skill type $i$ in this economy or that we increase the supply of a number of types. What is the effect of such changes in the skill distribution on relative wages? To answer this type of question, we need to know the values of the Hicks-Allen elasticities of complementarity, which measure the effect of a change in the supply of type $i$ on the wages of all types. As is well known, these elasticities can be derived easily from the second derivatives of the production function: the first derivative yields the marginal productivity of each type as a function of all inputs. In equilibrium, marginal productivity is equal to the wage. Hence, the second derivative yields the effect of changes in the input of any skill type on type $i$ 's wage rate. Regrettably, an explicit expression for this production function is not available, so that we have to revert to the more complex approach of deriving elasticities of complementarity from elasticities of substitution. Hicks-Allen elasticities of substitution measure the effect of changes in the wage of type $i$ on the input demand for all skill types. These elasticities can be derived from the second derivatives of the cost function: the first derivative yields input demand as a function of all wages. Hence, the second derivative yields the effect of changes in the wage of any skill type on type $i$ 's input demand. Since an explicit expression for the cost function is available, Hicks-Allen elasticities of substitution can be easily derived. From there, deriving Hicks-Allen elasticities of complementarity is just a problem of matrix inversion: going from a system of linear equations that specifies log inputs as a function of log wages to a system that specifies $\log$ wages as a function of log inputs. This is the exercise I undertake in this section. First, I derive Hicks-Allen elasticities of substitution from the cost function of the economy. Next, the system of linear log wage functions is inverted in order to derive the Hicks-Allen elasticities of complementarity.

\section{A. Substitution}

Hicks-Allen elasticities of substitution measure the effect of changes in log wages on log input demand:

$$
d \underline{n}=\mathbf{H V} d \underline{w}
$$


subject to

$$
0=p_{\underline{w}} d \underline{w},
$$

where $\underline{n} \equiv\left\{n_{i}\right\}, n_{i} \equiv \log N_{i}$, is a vector of $\log$ input demands; $\mathbf{H} \equiv$ $\left\{h_{i j}\right\}$ is an $I \times I$ matrix of elasticities of substitution; $\mathbf{V} \equiv\left\{v_{i}\right\}$ is an $I \times$ $I$ diagonal matrix of the value shares; and $p_{w}$ is the vector of partial derivatives of the cost function $p(\underline{w})$. The constraint $0=\underline{p}_{\underline{w}}(\underline{w}) d \underline{w}$ guarantees that the perturbation $d \underline{w}$ of input prices is such that the output price remains constant. As is well known, the off-diagonal elements of the matrix $\mathbf{H}$ are equal to the matrix of second derivatives of the $\log$ cost function $p(\underline{w})$, pre- and postmultiplied by the inverse matrix of value shares:

$$
\mathbf{H}_{\text {|off-diagonal }}=1+\mathbf{V}^{-1} p_{\underline{w w w}} \mathbf{V}^{-1}
$$

(see Sec. $A$ of App. B, in the online edition, for a formal proof). The application of this expression to the cost function for this economy, equation (5), yields the following proposition.

Proposition 2. Consider the economy described in Section II. Let $\Delta s \rightarrow 0$. The elasticities of substitution satisfy

1. $h_{i j, j \neq i-1, i, i+1}=0$;

2. $h_{i-1, i}=v\left(s_{i}\right) /\left[v_{i-1} v_{i} w^{\prime \prime}\left(s_{i}\right) \Delta s\right] ;$ and

3. $h_{i i}$ solves $\mathbf{H} \underline{V}=\underline{0}$, where $\lim _{\Delta s \rightarrow 0}\left(v_{i} / \Delta s\right) \equiv v\left(s_{i}\right), \underline{V} \equiv\left\{v_{i}\right\}$ is a vector of value shares, and $\underline{0}$ is a vector of zeros.

The derivation of this result is relegated to Appendix A. The function $v(s)$ can be interpreted as the density function of the value of input across $s$ for the limiting continuous case. The elasticities of substitution not adjacent to the main diagonal satisfy the Leontief result of a zero elasticity of substitution. Hence, a change in $w_{i}$ does not change input demand for $j \neq i-1, i, i+1$. Only employers of types $c_{i}$ and $c_{i+1}$ shift their labor demand from type $i$ to types $i-1$ and $i+1$, respectively, pushing up demand for these types. They were indifferent between using $i-1$ and $i$, and $i$ and $i+1$ before the increase of $w_{i}$ and therefore strictly prefer type $i-1$ and type $i+1$ after the increase. In equation (5), this can be seen from the fact that the cross derivatives of the boundaries of the integration intervals, $c_{i}\left(w_{i-1}, w_{i}\right)$ and $c_{i+1}\left(w_{i}, w_{i+1}\right)$, are nonzero for these entries only.

Proposition 2 has an important implication for empirical research into the value of elasticities of substitution between worker types. In the limit $I \rightarrow \infty, \Delta s \rightarrow 0$, the number of elements of $\mathbf{H}$ adjacent to the main diagonal relative to the total number of elements goes to zero. Hence, $\mathbf{H}$ converges to zero almost everywhere. Furthermore, $\lim _{\Delta s \rightarrow 0} h_{i j, j=i-1, i, i+1}$ does not exist. The entries on and adjacent to the main diagonal go to infinity when $\Delta s \rightarrow 0$. Elasticities of substitution are 
therefore not a useful concept for empirical research in the context of this model, since their value is not defined independent of the choice of $\Delta$ s. Elasticities of substitution depend strongly on the coarseness of the classification of worker types that is applied (see Teulings [2000] for an application to the effects of minimum wages). Let us therefore turn our attention to the elasticities of complementarity.

\section{B. Complementarity}

Hicks-Allen elasticities of complementarity measure the effect of changes in log inputs on log wages:

$$
d \underline{w}=\mathbf{E V} d \underline{n},
$$

where $\mathbf{E} \equiv\left\{e_{i j}\right\}$ is an $I \times I$ matrix of elasticities of complementarity. The matrix $\mathbf{E}$ can be derived from the inversion of the bordered Hessian matrix of elasticities of substitution:

$$
\mathbf{E}=\mathbf{V}^{-1}\left\{\mathbf{H}^{+^{-1}}\right\} \mathbf{V}^{-1}
$$

(see Sec. $B$ of App. B in the online edition for a formal proof), where $\mathbf{H}^{+}$is the "bordered" $(I+1) \times(I+1)$ matrix of substitution elasticities; bordering of the matrix takes account of the restriction that we consider price perturbations that leave the price of the composite commodity unaffected, $0=\underline{p}_{\underline{w}}(\underline{w}) d \underline{w} .{ }^{1}$ The braces denote an operator that drops the borders (the final column and row) of a matrix. This expression is applied to the elasticities of substitution presented in proposition 2 to obtain the elasticities of complementarity $e_{i j}$. One can write $e_{i j}$ as a function of two arguments, $s_{i}$ and $s_{j}: e\left(s_{i}, s_{j}\right) \equiv e_{i j}$. The following proposition characterizes $e\left(s_{i}, s_{j}\right)$.

Proposition 3. Consider the economy described in Section II. Let $\Delta s \rightarrow 0$. The elasticities of complementarity satisfy

$$
\begin{aligned}
e\left(s_{i}, s_{j}\right)_{s_{i}<s_{j}} & =-\int_{s^{-}}^{s_{i}} \frac{V(s)}{v(s)} w^{\prime \prime}(s) d s-\int_{s_{j}}^{s^{+}} \frac{1-V(s)}{v(s)} w^{\prime \prime}(s) d s+Q, \\
e\left(s_{i}, s_{j}\right)_{s_{i}>s_{j}} & =e\left(s_{j}, s_{i}\right)_{\mid s_{j}<s_{i},} \\
Q & \equiv \int_{s^{-}}^{s^{+}} v(x) \int_{s}^{x} \frac{V(s)}{v(s)} w^{\prime \prime}(s) d s d x, \\
V(s) & \equiv \int_{s^{-}}^{s} v(x) d x .
\end{aligned}
$$

${ }^{1}$ The matrix

$$
\mathbf{H}^{+} \equiv\left[\begin{array}{ll}
\mathbf{H} & \underline{1} \\
\underline{1}^{\prime} & 0
\end{array}\right],
$$

where $\underline{1} \equiv[1,1, \ldots, 1]^{\prime}$. 
Since $v(s)$ is the density function of the value of input, $V(s)$ is its distribution function. Hence $V\left(s^{-}\right)=0$ and $V\left(s^{+}\right)=1$. The proof of proposition 3 is in Appendix A. ${ }^{2}$

The complementarity matrix has some attractive features. The first and second terms in the first line of proposition 3 depend only on $s_{i}$ and $s_{j}$, respectively, and the third term is a constant. Hence, the cross derivative $e_{12}(\cdot)$ is equal to zero (the subscripts $i$ refer to the partial derivatives with respect to its $i$ th argument), and the first derivative has a simple structure:

$$
e_{1}\left(s_{i}, s_{j}\right)_{\mid s_{i}<s_{j}}=-\frac{V\left(s_{i}\right)}{v\left(s_{i}\right)} w^{\prime \prime}\left(s_{i}\right)
$$

The trajectory of $e\left(s_{i}, s_{j}\right)_{s_{s}<s_{j}}$ for a fixed $s_{j}$ starts flat from the lower support $s_{i}=s^{-}$since $V\left(s^{-}\right)=e_{1}\left(s^{-}, s_{j}\right)=0$. From there, it declines monotonically until it reaches a minimum value at the main diagonal. Beyond the main diagonal, the reverse is true. Hence, $e\left(s_{i}, s_{j}\right)$ is nondifferentiable at the main diagonal. The $e\left(s_{i}, s_{j}\right)$ locus is depicted in figure 1 for the case of a constant second derivative of the log wage function and a uniform distribution of value shares. The nondifferentiability at the main diagonal strikes out immediately. Obviously, the main diagonal is negative everywhere since the matrix of elasticities should be negative definite. Hence, this is a general feature holding for any $w(s)$ or $v(s)$. The same is true for the fact that the main diagonal is most negative at both extremes. The reason is that the trajectories of $e\left(s_{i}, s_{j}\right)$, with $s_{j}$ held constant, are parallel since $e_{12}(\cdot)=0$ (except for the main diagonal). Starting from the border of the matrix, where the trajectories are flat, the trajectories go down at an increasing rate. At both extremes, this process continues the longest and, hence, yields the most negative outcome. Hence, changes in labor supply have a much larger effect on relative wages for extreme skill types than for the median skill type. This explains why a reduction in the minimum wage, which is likely to in-

\footnotetext{
${ }^{2}$ The characterization of $e(\cdot)$ follows from the solution of a second-order differential equation in its first argument. It is instructive to see why this is the case. Let $\mathbf{G}^{+} \equiv$ $\mathbf{H}^{+-1}$ and let $g_{j}^{+}$and $\underline{h}_{i}^{+}$be their $j$ th and $i$ th column vectors. Since $\mathbf{G}^{+} \mathbf{H}^{+}=\mathbf{I}$ (the identity matrix), $\underline{g}_{j}^{+} \underline{h}_{i}^{+}=0$ for any $i \neq j$. Consider $\underline{h}_{i}^{+}$. By proposition $2, h_{i j}=0$ except for $j=$ $i-1, i, i+1$, and $I+1$ (the latter is the bordering element). Furthermore, $h_{i-1, i} \cong h_{i+1, i}$ for small $\Delta s$, since

$$
\lim _{\Delta s \rightarrow 0} \frac{v_{i-1}}{\Delta s}=\lim _{\Delta s \rightarrow 0} \frac{v_{i+1}}{\Delta s}=v\left(s_{i}\right),
$$

and $h_{i-1, i}+h_{i i}+h_{i+1, i} \cong 0$ (since $\underline{h}_{i}^{\prime} \underline{V}=0$ ). Hence

$$
0=g_{j}^{+{ }^{+}} \underline{h}_{i}^{+} \cong h_{i+1, i}\left(g_{i+1, j}-2 g_{i j}+g_{i-1, j}\right)+g_{j, I+1} h_{i, I+1} \Rightarrow
$$$$
g_{j, I+1} h_{i, I+1} \cong-h_{i+1, i} \Delta^{2} g_{i+1, j}
$$

since $\Delta^{2} g_{i+1, j} \equiv g_{i-1, j}-2 g_{i j}+g_{i+1, j}$.
} 


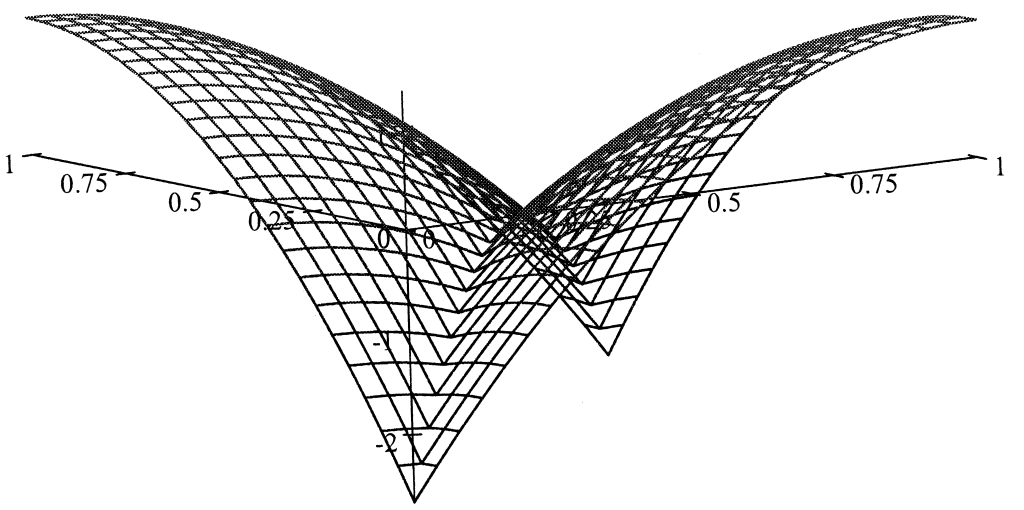

Fig. 1.-Plot of the $e\left(s_{i}, s_{j}\right)$ for $s^{-}=0, s^{+}=1, w^{\prime \prime}(s)=4$, and $v(s)=1$

crease effective labor supply for the least skilled worker types, has such a huge effect on relative wages (see Teulings 2000, 2003).

Figure $2 a$ depicts a slice of $e\left(s_{i}, s_{j}\right)$, with $s_{j}$ held constant; the left branch, $e\left(s_{i}, s_{j}\right)_{s_{i}<s_{j}}$, is a parabola with its top at $s_{i}=0$. At the main diagonal, $s_{i}=s_{i}$, the trajectory crosses the upward-sloping branch from a similar parabola with its top at $s_{i}=1$. The vertical position of both parabolas is determined by the requirement that the areas above and below the horizontal axis must have equal surface, since the value-weighted sum of complementarity effects is equal to zero. Figure $2 b$ shows the trajectory of $e_{1}\left(s_{i}, s_{j}\right)$. Owing to the uniform distribution of value shares, this first derivative has an interesting interpretation: ${ }^{3}$

$$
e_{1}\left(s_{i}, s_{j}\right)=\frac{d w^{\prime}\left(s_{i}\right)}{\Delta s d n_{j}}=\frac{d c_{i}}{\Delta s d n_{j}},
$$

where $d w^{\prime}\left(s_{i}\right) / \Delta s d n_{j}$ is the change in the return to skill due to the increase of the relative supply of type $s_{j}$, and $d c_{i} / \Delta s d n_{j}$ is the change in the task type $c_{i}$ to which a type $s_{i}$ worker is assigned as a result of that increase in supply. By equation (3), these are directly linked to each other; $e_{1}\left(s_{i}, s_{j}\right)$ therefore measures the change in assignment of workers to tasks. As figure $2 b$ shows, skill types $s_{i}<s_{j}$ are assigned to less complex tasks, whereas all skill types $s_{i}>s_{j}$ are assigned to more complex tasks. The

\footnotetext{
${ }^{3}$ Because of the uniform value distribution, $v_{i}=\Delta s$. Hence, eq. (7) reduces to

$$
d w_{i}=e\left(s_{i}, s_{j}\right) \Delta s d n_{j}
$$
}

Taking first differences with respect to $i$ and applying eq. (3) and

$$
\lim _{\Delta s \rightarrow 0} \frac{e\left(s_{i}, s_{j}\right)-e\left(s_{i-1}, s_{j}\right)}{\Delta s}=e_{1}\left(s_{i}, s_{j}\right)
$$

yields the equation in the text. 
a

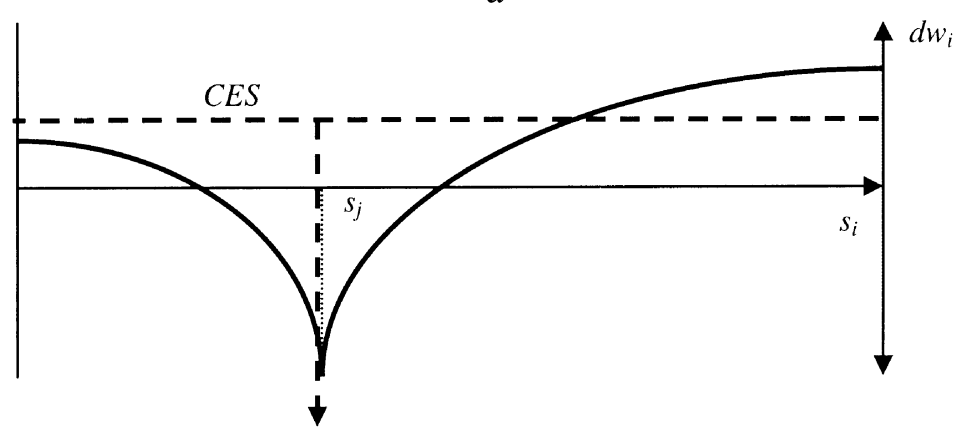

b

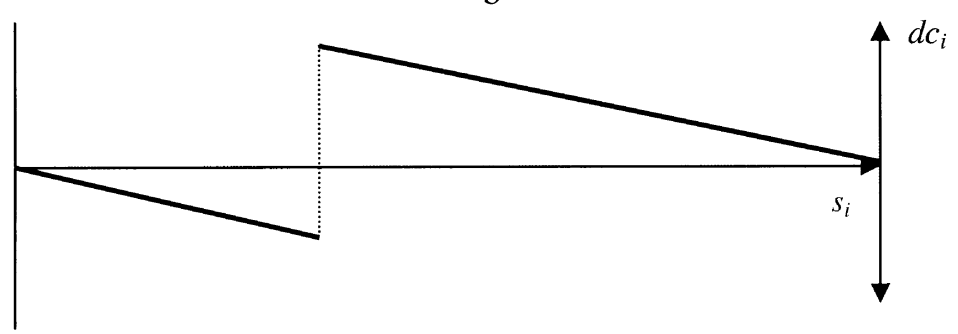

Fig. 2.-Complementarity effects due to a supply increase for type $j$. $a$, Effect on log wages $w(s): e\left(s_{i}, s_{j}\right) . b$, Effect on the assignment $c(s): e_{1}\left(s_{i}, s_{j}\right)$.

net effect is that a greater range of complexities $c_{j+1}-c_{j}$ becomes available for skill type $s_{j}$, which is required to provide tasks to the new type $s_{j}$ workers who enter the market. However, the least skilled worker type $s^{-}$will always be assigned to the least complex task $c^{-}$, whereas the most skilled worker type $s^{+}$will always be assigned to the most complex task $c^{+}$. This offers an economic intuition for why $e_{1}\left(s^{-}, s_{j}\right)=e_{1}\left(s^{+}, s_{j}\right)=0$. For similar reasons, the skill types adjacent to type $s_{j}$ experience the greatest shift in assignment. Since there is a one-to-one correspondence between $w^{\prime}\left(s_{i}\right)$ and $c_{i}$ (see eq. [3]), the change in assignment is directly related to the relative wage effects of the increase in the supply of type $s_{j}$. The second derivative $e_{11}\left(s_{i}, s_{j}\right)$ is a constant. Again, this has an economic interpretation. The additional type $s_{j}$ workers take part of the tasks previously occupied by other types. All other skill types have to give in a bit, all by the same fraction. The number of tasks available to type $s_{i}$ is equal to $c_{i+1}-c_{i}=\Delta c_{i+1}$. Since $d c_{i} / d n_{j}$ is proportional to $e_{1}\left(s_{i}, s_{j}\right), d \Delta c_{i} / d n_{j}$ is proportional to $e_{11}\left(s_{i}, s_{j}\right)$. The second derivative is therefore the change in the subset of tasks that is available for type $s_{i}$. It is constant and negative for all skill types, except for skill type $s_{j}$. 
Hence, all skill types lose the same percentage of their share in the support of $c$, to make room for the new workers of skill type $s_{j}$.

The new equilibrium wage locus results from a chain reaction of substitution effects, where the new type $s_{j}$ workers push some of the type $s_{j-1}$ and $s_{j+1}$ workers out of their tasks, who in turn push some of the type $s_{j-2}$ and $s_{j+2}$ workers out of their tasks, and so on. The substitution process materializes by spillover effects from one market segment to the other, in both the upward and the downward direction of the task hierarchy. All this invokes a chain of relative wage changes, where the wage of type $j$ is reduced the most and the wage reductions become smaller the further away from type $j$ we are. This is the essence of the DIDES structure. To visualize the contrast with the standard continuoustype CES structure à la Dixit and Stiglitz (1977), the locus of substitution elasticities for this production function is also plotted in figure $2 a$ as the dotted line. It shows an (infinitely large) ${ }^{4}$ negative spike at the own type $j$ and an equal and small positive effect for all other types.

The shape of the wage effects of changes in the supply of the extreme skill types can help to account for the specific form of the increase in wage inequality in the United States during the 1980s. Juhn et al. (1993) have documented that return to education has gone up for all wage levels more or less by the same amount during that period (see panel $\mathrm{D}$ in their fig. 4 on p. 418). However, the demand for skill has gone up only in the highest decile of the skill distribution (see panel D in their fig. 9 on p. 435). This combination of a demand increase only at the top and an across-the-board increase in the return to human capital has been a puzzle. The DIDES structure can explain why an increase in skill demand at the top has an effect on relative wages all across the board, which partly resolves the puzzle. However, the concave/convex shape of the curve in figure $2 a$ implies that the relative wage effects are the strongest at the point of the distribution at which skill demand is increased, which is inconsistent with the equiproportional increase in wage differentials that has actually occurred. But next to the increase in demand at the top, the fall in real minimum wages during the period is likely to have increased skill supply at the lowest percentile of the skill distribution: the people who could be profitably employed only after the fall in the minimum wage. Teulings (2003) has shown that the fall in minimum wages indeed had large effects on relative wages, consistent with figure $2 a$ : sharp declines in relative wages at the bottom of the distribution, which gradually die out higher up in the wage distri-

\footnotetext{
${ }^{4}$ Suppose that we increase supply for an interval $\Delta$ s. Since value-weighted complementarity effects sum to zero, 
bution. So, both the increase in demand at the extreme top and the increase in supply at the extreme bottom raised wage differentials, but both forces had their largest impact at different places in the wage distribution. However, the curvatures of the curves in figure $2 a$ associated with both forces offset each other. So, their net effect might have been the overall increase in wage differentials that has actually occurred.

\section{Relative Wages and Investment in Human Capital}

\section{A. The Complexity Dispersion Parameter}

While proposition 3 provides a useful characterization of elasticities of complementarity, the expression is not easily interpreted empirically. The wage distribution can be observed directly from the data. A direct empirical counterpart of $s$ is not available. Since $w^{\prime}(s)>0$, there is a one-to-one correspondence between the skill level and wages. Hence, we can characterize workers just as well by their wage as by their skill. It is therefore a useful idea to recast proposition 3 in terms of the distribution of $\log$ wages instead of skill. Let $\epsilon\left[w\left(s_{i}\right), w\left(s_{j}\right)\right] \equiv e\left(s_{i}, s_{j}\right)$. Then

$$
\begin{aligned}
\epsilon\left(w_{i}, w_{j}\right)_{\mid w_{i}<w_{j}} & =-\int_{w^{-}}^{w_{i}} \frac{F(w)}{f(w)} \gamma(w) d w-\int_{w_{j}}^{w^{+}} \frac{1-F(w)}{f(w)} \gamma(w) d w+Q, \\
Q & =\int_{w^{-}}^{w^{+}} f(x) \int_{w}^{x} \frac{F(w)}{f(w)} \gamma(w) d w d x,
\end{aligned}
$$

where

$$
\gamma\left[w\left(s_{i}\right)\right] \equiv \frac{w^{\prime \prime}\left(s_{i}\right)}{w^{\prime}\left(s_{i}\right)^{2}}=\lim _{\Delta s \rightarrow 0} c_{i}^{-2} \frac{\Delta c_{i}}{\Delta s},
$$

$F[w(s)] \equiv V(s)$ is the distribution of value across wages $^{5}$ (hence $v(s)=$ $\left.f[w(s)] w^{\prime}(s)\right), w^{-} \equiv w\left(s^{-}\right)$, and $w^{+} \equiv w\left(s^{+}\right)$. Elasticities of complementarity are therefore fully defined in terms of the wage distribution, which is directly observable from the data, and the parameter $\gamma(w)$ is defined in (9). This parameter incorporates the role of the second derivative of the wage function. By equation (3), $w^{\prime \prime}\left(s_{i}\right)=\lim _{\Delta s \rightarrow 0} \Delta c_{i} / \Delta s$. Hence $w^{\prime \prime}(s)$ can be interpreted as a measure of the dispersion of $c$ per unit of s. I refer to $\gamma(w)$ as the complexity dispersion parameter. It measures the degree of comparative advantage in the economy. If this parameter is

\footnotetext{
${ }^{5}$ The function $F(w)$ differs from the standard log wage distributions, which refer to hours worked or persons employed instead of value. Let $r(w)$ be the density function of the standard wage distribution. Then

$$
f(w)=\frac{r(w) \exp (w)}{\int_{w^{-}}^{w^{+}} r(x) \exp (x) d x} .
$$
}


equal to zero for all $w_{i}$, then it must be the case that $\Delta c_{i}=0$ for all $i$, so that all skill types are employed in the same job type. In that case, we are back in a homogeneous world in which workers differ by their productivity but are perfect substitutes.

The complexity dispersion parameter has another, intuitive interpretation. Consider the continuous version of the model, $\Delta s \rightarrow 0$. Suppose that a type $c$ firm hires a type $s$ worker who is not exactly the costminimizing type and pays this worker her equilibrium log wage $w(s)$. The log cost function per efficiency unit of labor of type $s$ is $w(s)-$ $c_{i}$ s. A second-order Taylor expansion of this cost function around the cost-minimizing skill type $s_{i}$ is

$$
p_{c_{i}}=w\left(s_{i}\right)-c_{i} s_{i}+\frac{1}{2} w^{\prime \prime}\left(s_{i}\right)\left(s-s_{i}\right)^{2} .
$$

The first-order term drops out by the envelope theorem. The final term is the excess cost of an out-of-equilibrium assignment. Hiring a better(or worse-) skilled worker than the optimal type raises (lowers) productivity, but this effect is more (less) than offset by the higher (lower) wage bill. The excess cost is therefore a second-order effect. Instead of expressing this excess cost as a function of the skill differential relative to the optimal skill type, $s-s_{i}$, I can also express it as a function of the $\log$ wage differential relative to the optimal wage level, $x \% \equiv w-$ $w_{i}=\left(s-s_{i}\right) / w^{\prime}(s)$; hence, $x$ is the percentage deviation from the optimal wage level. The excess cost as a function of this percentage deviation from the optimal wage is proportional to the complexity dispersion parameter:

$$
\frac{1}{2} w^{\prime \prime}\left(s_{i}\right)\left(s-s_{i}\right)^{2}=\frac{1}{2} \frac{w^{\prime \prime}\left(s_{i}\right)}{w^{\prime}\left(s_{i}\right)^{2}}(x \%)^{2}=\frac{1}{2} \gamma\left(w_{i}\right)(x \%)^{2} .
$$

The complexity dispersion parameter can therefore be interpreted as the curvature of the cost function of the production of task type $c_{i}$, where the costs are expressed as a function of log wages instead of skill types (or, alternatively, where skill types are indexed by the wage they command). In terms of Rosen's (1974) famous imagery of cost curves kissing the hedonic price function, $w(s)$ is the hedonic price function, and the complexity dispersion parameter is the curvature of the kissing cost function. The concept of a complexity dispersion parameter therefore has an important role to play when extending the Walrasian assignment model with search frictions. In such a world, job seekers face a trade-off between the cost of accepting the suboptimal assignment of the current job offer and the revenues of continued search for a better assignment. Then, the complexity dispersion parameter measures the cost of suboptimal assignment (see Teulings and Gautier 2004).

The complexity dispersion parameter is not a structural technological 
parameter like the elasticity of substitution of a CES production function. This can be seen immediately from the fact that its definition depends on the endogenous locus $w(s)$. The parameter may vary along the domain of $s$ within a particular economy and between economies, for example, by differences in the distributions of either skill supply, $\chi(s)$, or complexity demand, $\delta(c)$, analogous to value shares in a CES function, which change by shifts in factor inputs.

A crucial feature of the complexity dispersion parameter is its insensitivity to a linear transformation of the skill variable. ${ }^{6}$ The relevance of this feature is that the metric of $s$ can be established empirically only up to a linear transformation (see Teulings 1995, 301). ${ }^{7}$ Statements such as "the variance of $s$ is such and such" are therefore devoid of any empirical content. To the contrary, the statement "the complexity dispersion parameter is two" has a clear empirical interpretation. I shall return to this issue in Section V. When between-economy variation in either $\delta(c)$ or $\chi(s)$ is available, the complexity dispersion parameter can be estimated (see Teulings 1995).

\section{B. The Distributive Effects of Additional Human Capital}

The framework developed so far can be used for many applications. One application, the acquisition of additional human capital, deserves special attention since it reveals some remarkable characteristics of this production structure. Let us consider a pattern of increases in human capital by one step $\Delta s$ for a fraction $q\left(s_{j}\right)$ of the type $s_{j}$ workers. Hence, a fraction $q\left(s_{j}\right)$ of the type $s_{j}$ workers (the "source" type) is moved to type $s_{j+1}=s_{j}+\Delta s$ (the "destination" type). I take it that $q\left(s_{j}\right)$ is a small number such that $\ln \left[1-q\left(s_{j}\right)\right] \cong-q\left(s_{j}\right)$. This setup can capture any distribution of additional human capital across skill types. At first sight, it seems restrictive to consider increases in human capital by only a single step $\Delta s$. However, in the limit for $\Delta s \rightarrow 0$, it does not matter whether a share $q\left(s_{j}\right)$ of type $s_{j}$ increases its skill by $\Delta s$ or a share $\frac{1}{2} q\left(s_{j}\right)$ increases its skill by $2 \Delta s$.

The direct effect of this additional human capital on the wage distribution keeps log wages per skill type, $w\left(s_{j}\right)$, constant and accounts for

\footnotetext{
${ }^{6}$ Let $\bar{s}(s) \equiv \alpha_{0}+\alpha_{1} s, \alpha_{1}>0$, be an alternative, linearly transformed skill variable, and let $\bar{w}(s)$ be log wages as a function of the transformed skill index, such that $\bar{w}\left(\alpha_{0}+\right.$ $\left.\alpha_{1} s\right)=w(s)$. It is checked easily that $w^{\prime \prime}(s) / w^{\prime}(s)^{2}=\bar{w}^{\prime \prime}[\bar{s}(s)] / \bar{w}^{\prime}[\bar{s}(s)]^{2}$.

${ }^{7}$ Any linear transformation of $s$ can be offset by an opposite transformation of $c$ and an appropriate redefinition of the units of measurement of type $c$ tasks. Define $\bar{s}$ as in n. 6 and $\bar{c} \equiv \alpha_{1}^{-1} c$. Then$$
f(\bar{s}, \bar{c})=\exp (\bar{s} \bar{c})=\exp (s c) \exp \left(\alpha_{0} \alpha_{1}^{-1} c\right)=f(s, c) \exp \left(\alpha_{0} \alpha_{1}^{-1} c\right) .
$$

The second factor is equivalent to a redefinition of the units of measurement of task type $c$. Since the output of tasks has no empirical counterpart, this redefinition can be carried through without further consequence.
} 
the fact that a fraction $q\left(s_{j}\right)$ of skill type $s_{j}$ is moved to the next skill type $s_{j+1}$; therefore, their log wage is increased from $w_{j}=w\left(s_{j}\right)$ to $w_{j+1}=$ $w\left(s_{j+1}\right)$. Next to this direct effect, however, there is a general equilibrium effect. The upward shift in the skill distribution changes $w\left(s_{j}\right)$ itself. The magnitude of this general equilibrium effect can be calculated from proposition 4 .

Proposition 4. Consider the economy described in Section II, and suppose that for each type $s_{j}$ the skill level of a fraction $q\left(s_{j}\right)$ is increased by an amount $\Delta s$. Then, for $\Delta s \rightarrow 0$, the change in the log wage of type $s_{i}$ per unit increase $\Delta s$ satisfies

$$
\begin{aligned}
\frac{d w_{i}}{\Delta s}= & \int_{w^{-}}^{w^{+}}\left[\epsilon_{2}\left(w_{i}, w\right)+\epsilon\left(w_{i}, w\right)\right] f(w) h(w) d w \\
= & -\int_{w^{-}}^{w_{i}} F(w) \gamma(w) h(w) d w+\int_{w_{i}}^{w^{+}}[1-F(w)] \gamma(w) h(w) d w \\
& +\int_{w^{-}}^{w^{+}} \epsilon\left(w_{i}, w\right) f(w) h(w) d w,
\end{aligned}
$$

where $h[w(s)] \equiv q(s) w^{\prime}(s)$.

The concept $h[w(s)] \Delta s$ is the relative increase in the stock of human capital of all workers of source type $s$ evaluated at market prices, $q(s)$ is the fraction of workers who take the increase $\Delta s$, and $w^{\prime}(s)$ is the market valuation of a unit increase in $s$. In fact, $w^{\prime}(s)$ is the relative wage increase per unit of additional skill or, equivalently, the Mincerian rate of return to human capital.

I present the proof of proposition 4 in the text since it is instructive for the subsequent argument. Consider the effect of the human capital acquisition of type $s_{j}$ on the distribution of labor supply. Since a fraction $q\left(s_{j}\right)$ leaves the source type $s_{j}$, we have $d n_{j}=-q\left(s_{j}\right)$; and since these workers move toward the destination type $s_{j+1}$, we have $-d N_{j}=d N_{j+1}$. Since $v_{j}=W_{j} N_{j} / \sum_{i} W_{i} N_{i}$,

$$
\begin{aligned}
v_{j} d n_{j} & =W_{j} d N_{j}, \quad v_{j+1} d n_{j+1}=W_{j+1} d N_{j+1} \Rightarrow \\
-\frac{W_{j+1}}{W_{j}} v_{j} d n_{j} & =v_{j+1} d n_{j+1} .
\end{aligned}
$$


Substitution of this expression in equation (7) yields

$$
\begin{aligned}
\frac{d w_{i}}{\Delta s} & =\lim _{\Delta s \rightarrow 0} \sum_{j=1, I-1} \frac{1}{\Delta s}\left[e\left(s_{i}, s_{j+1}\right) \frac{W_{j+1}}{W_{j}}-e\left(s_{i}, s_{j}\right)\right] v_{j} q\left(s_{j}\right) \\
& =\int_{s^{-}}^{s^{+}}\left[e_{2}\left(s_{i}, s\right)+e\left(s_{i}, s\right) w^{\prime}(s)\right] v(s) q(s) d s \\
& =\int_{w^{-}}^{w^{+}}\left[\epsilon_{2}\left(w_{i}, w\right)+\epsilon\left(w_{i}, w\right)\right] f(w) h(w) d w .
\end{aligned}
$$

The first line states that the supply of the source type $s_{j}$ is decreased by $v_{j} d n_{j}$ and that of the destination type $s_{j+1}$ is increased by $\left(W_{j+1} / W_{j}\right) v_{j} d n_{j}$. The second line decomposes the term in brackets in

$$
\left[e\left(s_{i}, s_{j+1}\right)-e\left(s_{i}, s_{j}\right)\right]+e\left(s_{i}, s_{j+1}\right) \frac{W_{j+1}-W_{j}}{W_{j}}
$$

and takes the limit of $\Delta s \rightarrow 0$. The final line applies a transform of variable from $s$ to $w$ similarly to Section IV.A, using $v(s)=f[w(s)] w^{\prime}(s)$. The final equality in proposition 4 substitutes $\epsilon_{2}\left(w_{i}, w\right)$ for equation (8). QED

Proposition 4 reveals that the general equilibrium effect of the additional human capital can be decomposed into two parts, the composition effect - the term $\epsilon_{2}\left(w_{i}, w\right)$ in the first equality of proposition 4-and the extension effect-the term $\epsilon\left(w_{i}, w\right)$. The composition effect refers to the change in the composition of labor supply, and the extension effect is associated with the increase in total productivity by the additional human capital. As proposition 4 shows, both effects have the same order of magnitude. They can be explained most easily by considering the acquisition of human capital by type $s_{j}$ separate from the acquisition by other types, that is, $h\left(w_{i, i \neq j}\right)=0$. For this special case, proposition 4 implies

$$
\begin{aligned}
& \frac{d w_{i, i<j}}{\Delta s}=\left\{\left[1-F\left(w_{j}\right)\right] \gamma\left(w_{j}\right)+\epsilon\left(w_{i}, w_{j}\right) f\left(w_{j}\right)\right\} h\left(w_{j}\right) w^{\prime}\left(s_{j}\right) \Delta s, \\
& \frac{d w_{i, i>j}}{\Delta s}=\left[-F\left(w_{j}\right) \gamma\left(w_{j}\right)+\epsilon\left(w_{i}, w_{j}\right) f\left(w_{j}\right)\right] h\left(w_{j}\right) w^{\prime}\left(s_{j}\right) \Delta s .
\end{aligned}
$$

The first term in braces is the composition effect, and the second term is the extension effect.

The composition effect is due to the shift of some labor supply from the source type $s_{j}$ to the destination type $s_{j+1}$. These effects are depicted graphically in figure 3 , which repeats figure 2 , but now combining the negative effect on the supply of the source type and the positive effect 

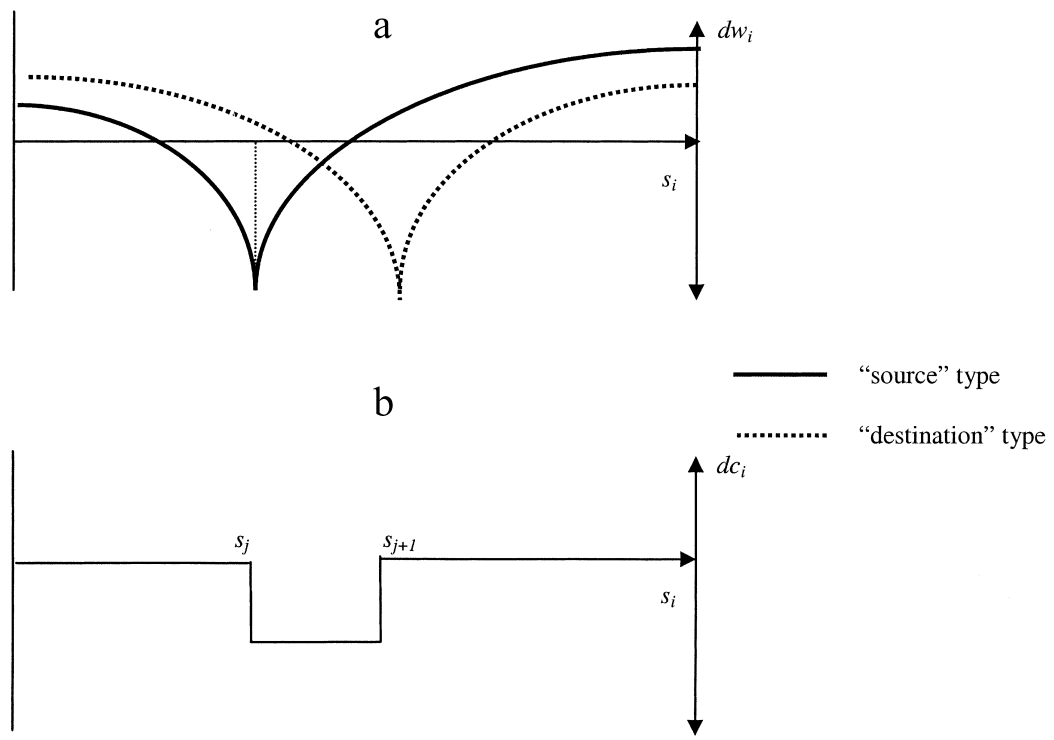

Fig. 3.-Composition effect of human capital accumulation. $a$, Effect on log wages. $b$, Effect on the assignment of worker types to tasks.

on the destination type. In figure $3 a$, the continuous line is the effect of the reduction of the supply of the source type, and the dotted line is minus the effect of the increase of the destination type. Hence, the wage goes up when the dotted line is above the continuous line, which is the case for $s_{i}<s_{j}$. The reverse applies for $s_{i}>s_{j+1}$. Figure $3 b$ shows the effect on the assignment of worker types to tasks. The labor supply of type $s_{j}$ is reduced by a fraction $q\left(s_{j}\right)$. Hence, the remaining workers of this type can serve fewer type $c$ tasks. The labor supply of type $s_{j+1}$ is increased by the same amount. The tasks no longer served by type $s_{j}$ will now be served by type $s_{j+1}: c_{j+1}$ goes down. The assignment of other worker types remains unaffected: $c_{i, i \neq j+1}$ is unchanged.

The implication of this analysis is that the composition effect of any increase in the stock of human capital compresses the wage distribution. The wages of worker types skilled less than type $s_{j}$ are increased, and all by the same amount; see the first term between braces in equation (11), which does not depend on $i$, and the wages for types $s_{i}>s_{j+1}$ are reduced, also all by the same amount. A share $F(w)$ gets a wage increase of $1-F(w)$, whereas a share $1-F(w)$ gets a wage reduction of $F(w)$, so that both cancel in aggregate. For example, the composition effect of any additional human capital between the tenth and ninetieth percentiles of the skill distribution decreases the 10-90 log wage differential. This is a somewhat surprising conclusion since the assignment of workers 
to tasks remains unaffected, except for $c_{j+1}$. Equation (3), $\lim _{\Delta s \rightarrow 0} c_{i}=$ $w^{\prime}\left(s_{i}\right)$, offers the explanation for this puzzle. Since $c_{j+1}$ goes down whereas all other $c_{i}$ remain unaffected, the slope of the wage function goes down between $s_{j}$ and $s_{j+1}$ but remains unchanged everywhere else. However, this implies that the level of the wages must go up for less skilled workers and go down for more skilled workers.

The extension effect accounts for the fact that the increase in the labor supply of the destination type $s_{j+1}$ is larger than the decrease of the source type $s_{j}$ when evaluated at market prices. This is the factor $W_{j+1} / W_{j}>1$ in equation (10). The market value of this increase is equal to the value of the additional human capital. Hence, the net effect on the supply of the source type $s_{j}$ and the destination type $s_{j+1}$ together is positive. The effect of this extension of labor supply on relative wages and on the assignment of workers to tasks can be read directly from figure $2 a$ : it shows that the wage of types $s_{j}$ and $s_{j+1}$ goes down the most and that this negative effect is smaller for skill types at a greater distance and becomes eventually positive. Figure $2 b$ shows the effect on the assignment of workers to jobs. Since the supply of types $s_{j}$ and $s_{j+1}$ together has been increased, they serve a greater range of tasks, leaving a smaller range for either less or more skilled workers.

The extension effect can be neutralized by the following thought experiment. Suppose that we let a fraction $q\left(s_{j}\right)$ of type $s_{j}$ obtain $\Delta s$ additional human capital. This raises their productivity by $w^{\prime}\left(s_{j}\right) \Delta s$. At the same time, we force a fraction $q\left(s_{j}\right) w^{\prime}\left(s_{j}\right) \Delta s$ of the workforce of type $s_{j+1}$ to leave the workforce. Then total productivity remains constant. However, we are left with a shift in the composition of the workforce, since some workers are moved from type $s_{j}$ to type $s_{j+1}$. This is the case that is represented in figure 3: only $c_{j+1}$ changes, and all other $c_{i}^{\prime}$ s are unaffected.

The total effect of the human capital acquisition can be represented by adding figure 2 (for the extension effect) and figure 3 (for the composition effect). As discussed, the composition effect leads unequivocally to a compression of wage dispersion. Figure 2 shows that the impact of the extension effect on wage dispersion depends on the position in the wage distribution. A human capital acquisition at the bottom increases dispersion (since it mainly raises wages at the top), whereas an acquisition at the top decreases it (since it mainly raises wages at the bottom).

Corollary 1. Consider an equiproportional increase in the value of human capital for all $s_{j}: h\left(w_{j}\right)=h$. The extension effects of this additional human capital on relative wages cancel.

Corollary 1 follows from the fact that complementarity effects add up 
to zero:

$$
\int_{w^{-}}^{w^{+}} \epsilon\left(w_{i}, w\right) f(w) d w=0
$$

Hence, the term in the last line of proposition 4 cancels. The intuition for this result is that an increase in the value of the human capital by an equal percentage for all worker types leads to an equal extension effect for all types. Hence, the sum of the extension effects is equal to an increase in labor supply for all types by an equal percentage. Since the economy described in Section II is characterized by constant returns to scale, an equiproportional increase in the labor supply of all worker types does not affect relative wages.

Corollary 2. Consider an equiproportional increase in human capital, $h\left(w_{j}\right)=h$, in an economy in which the complexity dispersion parameter is constant: $\gamma\left(w_{j}\right)=\gamma$. Then

$$
\frac{d\left[\ln w^{\prime}(s)\right]}{h \Delta s}=-\gamma
$$

The proof of corollary 2 applies proposition 4:

$$
\frac{d w_{i}-d w_{j}}{\Delta s}=-\left(w_{i}-w_{j}\right) \gamma h+h \int_{w^{-}}^{w^{+}}\left[\epsilon\left(w_{i}, w\right)-\epsilon\left(w_{j}, w\right)\right] f(w) d w .
$$

By corollary 1, the extension effects (the second term) cancel. Dividing both sides by $\left(w_{i}-w_{j}\right) / \Delta s$ and using

$$
\lim _{j \rightarrow i} \frac{d w_{i}-d w_{j}}{w_{i}-w_{j}}=\frac{d w^{\prime}(s)}{w^{\prime}(s)}=d\left[\ln w^{\prime}(s)\right]
$$

yields corollary 2. QED

The case of a constant complexity dispersion parameter provides, therefore, a useful benchmark. It implies that the curvature of the cost function for a specific task type $c$, or alternatively the cost of an out-ofequilibrium assignment, is the same for all tasks. In the next section, I provide a simple specification of the supply of and demand for skill that generates a constant complexity dispersion parameter. Since the extension effects of an equiproportional increase in human capital cancel as a result of corollary 1 and since the composition effect yields a compression of the wage distribution, the combined impact of both effects is a compression. Corollary 2 provides a simple and useful rule of thumb for the magnitude of this compression: the percentage reduction in the Mincerian rate of return to human capital, per percentage increase in the stock of human capital, is equal to the complexity dispersion pa- 
rameter. Alternatively, the complexity dispersion parameter can therefore be interpreted as a compression elasticity.

These results on the compression and extension effect have strong policy implications. Heckman et al. (1998a, 1998b) have argued that standard methods for analyzing the returns to training programs are biased since they ignore general equilibrium effects on wages. The DIDES model provides strong support for this notion. As long as the program is experimental and only a limited number of people are actually treated (the fraction of type $s$ workers who obtain additional human capital, $q(s)$, is small), the shift in the skill distribution will be too small to affect skill prices. Then, a training program will have only partial equilibrium effects; that is, the training program can be evaluated taking $w(s)$ as given. However, the more people are treated by the program $(q(s)$ is large), the greater the importance of the general equilibrium effect. Then skill prices will be affected, which reduces the effectiveness of the program.

\section{Relative Wages, Human Capital Accumulation, and Skill-Biased Technical Change}

So far, I have considered a completely general formulation of the distribution of skill supply and complexity demand, $\chi(s)$ and $\delta(c)$, respectively. In this section, I make some convenient parametric assumptions on these distributions. The framework developed in Section IV can then be applied to analyze the effects of shifts in the parameters of the skill distribution on the locus of relative wages. An important feature of these parametric assumptions is that they include the special case analyzed in corollary 2, where both the human capital acquisition $h$ and the complexity dispersion parameter $\gamma$ are independent of $s$. For the purpose of this exercise, it is convenient to use transformed skill and complexity variables $\bar{s}$ and $\bar{c}$, respectively, which are defined as ${ }^{8}$

$$
\begin{aligned}
& \bar{s}(s) \equiv-\ln (-s) \quad \forall s>0, \\
& \bar{c}(c) \equiv \ln (c) \quad \forall c>0 .
\end{aligned}
$$

Both representations of the model, either in terms of $s$ or in terms of $\bar{s}$, have their pros and their cons. The advantage of the representation in terms of $s$ used so far is the linearity of $\log$ output of task $c$ in $s$, leading to a simple first-order condition for optimal assignment, $w^{\prime}\left(s_{i}\right)=c_{i}$. The advantage of the transformed skill variable $\bar{s}$ is that the

\footnotetext{
${ }^{8}$ The choice $s^{+}=0$ is just a normalization: the implications of the model are invariant to a linear transformation of $s$ (see n. 7). Hence, we can always transform the skill variable to normalize its upper support to zero. Note that the model is not invariant to a linear transformation of $\bar{s}$, since $\bar{s}$ is a nonlinear transformation of $s$.
} 
wage function is linear in $\bar{s}$ for the special case in which the complexity dispersion parameter is independent of $w, \gamma(w)=\gamma$. This follows immediately from equation (9) and the definition of $\bar{s}^{9}$

$$
\bar{\gamma}(\bar{s})=\frac{1}{\bar{w}^{\prime}(\bar{s})}+\frac{\bar{w}^{\prime \prime}(\bar{s})}{\bar{w}^{\prime}(\bar{s})^{2}},
$$

where I apply the convention that a function with a bar on top is the equivalent of that function without a bar, but now as a function of the transformed skill variable $\bar{s}$; so $\bar{w}[\bar{s}(s)] \equiv w(s)$ and $\bar{\gamma}[\bar{s}(s)] \equiv \gamma[w(s)]$. Equation (13) reveals that $\bar{\gamma}(\bar{s})=\gamma$ if and only if $\bar{w}^{\prime \prime}(\bar{s})=0$. Assumption B parameterizes the distribution of skill supply and complexity demand.

Assumption B. (1) $\bar{s} \backsim N\left(\mu_{s}, \sigma_{s}^{2}\right)$, and (2) $\bar{c} \backsim N\left(\mu_{c}, \sigma_{c}^{2}\right)$.

Parts 1 and 2 of assumption B implicitly define the functions $\chi(s)$ and $\delta(c)$ as the density function of a lognormal distribution, with a minus sign for $s$ (see Sec. $B$ of App. B in the online edition for details). So, both the distribution of skill supply and complexity demand are characterized by two parameters. How do the locus of log wages and the complexity dispersion parameter change in response to shifts in the parameters of skill supply, with the distribution of complexity demand held constant? The functions $\bar{w}(\cdot)$ and $\bar{\gamma}(\cdot)$ are extended with arguments for the parameters of the skill distribution, $\bar{w}\left(\bar{s} ; \mu_{s}, \sigma_{s}\right)$ and $\bar{\gamma}\left(\bar{s} ; \mu_{s}, \sigma_{s}\right)$. I adopt the convention that $\bar{w}^{\prime}\left(\bar{s} ; \mu_{s}, \sigma_{s}\right)$ refers to the partial derivative with respect to $\bar{s}$. Proposition 5 considers the effect of shifts in $\mu_{s}$ on $\log$ wages, with $\sigma_{s}$ held constant at $\sigma_{c}$.

Proposition 5. Consider the economy described in Section II, satisfying assumption B. Assume $\sigma_{s}=\sigma_{c}$. Then

$$
\begin{aligned}
& \bar{w}\left(\bar{s} ; \mu_{s}, \sigma_{c}\right)=e^{\Delta \mu}\left(\bar{s}-\mu_{s}\right)-\frac{1}{2} e^{2 \Delta \mu} \sigma_{c}^{2}-e^{\Delta \mu}, \\
& \bar{\gamma}\left(\bar{s} ; \mu_{s}, \sigma_{c}\right)=e^{-\Delta \mu},
\end{aligned}
$$

where $\Delta \mu \equiv \mu_{c}-\mu_{s}$.

Proposition 5 is proved in online Appendix B. Conditional on an appropriate initial condition for $\bar{w}\left(\bar{s} ; 0, \sigma_{c}\right)$, the proposition is an immediate consequence of corollary 2. This corollary applies if both the complexity dispersion parameter $\gamma$ and the increase in human capital $h$ do not depend on $\bar{s}$. Since $\bar{w}\left(\bar{s} ; \mu_{s}, \sigma_{c}\right)$ is linear in $\bar{s}, \bar{\gamma}\left(\bar{s} ; \mu_{s}, \sigma_{c}\right)$ does

${ }^{9}$ Since

$$
\begin{aligned}
& w^{\prime}(s)=\bar{w}^{\prime}(\bar{s}) \bar{s}^{\prime}(s)=-\frac{\bar{w}^{\prime}(\bar{s})}{s}, \\
& w^{\prime \prime}(s)=\bar{w}^{\prime \prime}(\bar{s}) \bar{s}^{\prime}(s)^{2}+\bar{w}^{\prime}(\bar{s}) \bar{s}^{\prime \prime}(s)=\frac{\bar{w}^{\prime \prime}(\bar{s})+\bar{w}^{\prime}(\bar{s})}{s^{2}} .
\end{aligned}
$$


not depend on $\bar{s}$ (see eq. [13]). An increase in $\mu_{s}$ shifts the human capital of each worker type $\bar{s}$ up by the same amount $d \mu_{s}$. Since $\bar{h}(\bar{s}) \Delta s=\bar{w}^{\prime}\left(\bar{s} ; \mu_{s}, \sigma_{c}\right) d \mu_{s}$ and since $\bar{w}\left(\bar{s} ; \mu_{s}, \sigma_{c}\right)$ is linear in $\bar{s}, h$ does not depend on $\bar{s}$ either. Hence, corollary 2 applies:

$$
\frac{d\left(\ln \bar{w}^{\prime}\right)}{h \Delta s}=\bar{w}^{{ }^{-2}} \frac{d \bar{w}^{\prime}}{d \mu_{s}}=-\gamma .
$$

Since the reduction of $\bar{w}^{\prime}$ is constant, $d \bar{w}^{\prime \prime} / d \mu_{s}=0$. A change in $\mu_{s}$ therefore maintains the linearity of $\bar{w}\left(\bar{s} ; \mu_{s}, \sigma_{c}\right)$, and hence $\gamma=1 / \bar{w}^{\prime}$ (see eq. [13]). Then corollary 2 reduces to a differential equation $d \bar{w}^{\prime} / d \mu_{s}=$ $-\bar{w}^{\prime}$, which solves as $\bar{w}^{\prime}\left(\bar{s} ; \mu_{s}, \sigma_{c}\right)=e^{\Delta \mu}$. The combination of a linear log wage function and the normality of the skill distribution implies that log wages are distributed normally with $\mathrm{V}[w]=\bar{w}^{\prime 2} \sigma_{s}^{2}=\gamma^{-2} \sigma_{s}^{2}$, which is a reasonable description of empirical wage distributions.

Proposition 5 provides an analytical solution to the assignment problem for the case in which the skill distribution is a function of a single parameter, $\mu_{s}$. The only other example of an analytical solution that I am aware of is Tinbergen's (1956) seminal paper, which allows for the variation in even two parameters, the mean and the variance. However, that paper considers a model of compensating differentials, which is less attractive for the analysis of the accumulation of human capital. Each percent increase in the value of the stock of human capital reduces the return to further increases by $\gamma$ percent. That is the reason why $\gamma$ can be interpreted as a compression elasticity. At the same time, that additional percent of human capital raises the complexity dispersion parameter $\gamma$ by another $\gamma$ percent. Hence, each new increase in the value of human capital has an ever-larger negative effect on the return. The maximum output gain that can be achieved by human capital accumulation, with technology held constant, is equal to the inverse of the complexity dispersion parameter:

$$
\int_{\mu_{s}}^{\infty} \bar{w}_{\bar{s}}\left(\bar{s} ; x, \sigma_{c}\right) d x=\int_{\mu_{s}}^{\infty} e^{\mu_{c}-x} d x=\bar{\gamma}\left(\bar{s} ; \mu_{s}, \sigma_{c}\right)^{-1} .
$$

During this accumulation process, the return to human capital gradually falls, so that a 1 percent further addition to the value of the stock of human capital requires an ever-increasing physical addition $d \mu_{s}$. In the limit, the return is zero, so that each further physical increase does not yield any additional value of human capital. Skill-biased technological change can offset the negative effect of human capital accumulation on its return, so that new options for gainful accumulation of human capital arise. In the model, this is captured by a rise in $\mu_{c}$, accompanied by a general increase in the efficiency of the production process for the composite commodity. The rise in $\mu_{c}$ undoes the general equilibrium 
effects of an increase in $\mu_{s}$. This process is equivalent to Tinbergen's race between education and technology.

Contrary to Tinbergen's (1956) model, the analysis of variations in $\sigma_{s}$ does not have an analytical solution. Instead, let us consider a Taylor expansion of the solution starting from $\sigma_{s}=\sigma_{c}$, which applies for small values of $\left(\sigma_{s}-\sigma_{c}\right)^{2}$.

Proposition 6. Consider the economy described in Section II, satisfying assumption $\mathrm{B}$. Then

$$
\begin{aligned}
\bar{w}\left(\bar{s} ; \mu_{s}, \sigma_{s}\right)= & e^{\Delta \mu}\left[\left(\bar{s}-\mu_{s}\right)-e^{\Delta \mu} \sigma_{s}\left(\sigma_{s}-\sigma_{c}\right)\left(\bar{s}-\mu_{s}\right)\right. \\
& \left.-\frac{1}{2} \frac{\sigma_{s}-\sigma_{c}}{\sigma_{s}}\left(\bar{s}-\mu_{s}\right)^{2}\right]-\frac{1}{2} e^{2 \Delta \mu} \sigma_{c}^{2}-e^{\Delta \mu} \\
& +\frac{1}{2} e^{\Delta \mu} \sigma_{c}\left(1+3 e^{2 \Delta \mu} \sigma_{c}^{2}\right)\left(\sigma_{s}-\sigma_{c}\right)+O\left[\left(\sigma_{s}-\sigma_{c}\right)^{2}\right], \\
\bar{\gamma}\left(\bar{s} ; \mu_{s}, \sigma_{c}\right)= & e^{-\Delta \mu}\left[\frac{\sigma_{c}}{\sigma_{s}}+e^{\Delta \mu} \sigma_{s}\left(\sigma_{s}-\sigma_{c}\right)+\frac{\sigma_{s}-\sigma_{c}}{\sigma_{s}}\left(\bar{s}-\mu_{s}\right)\right] \\
& +O\left[\left(\sigma_{s}-\sigma_{c}\right)^{2}\right],
\end{aligned}
$$

where $O[\cdot]$ is the standard order function.

The proof is in Section $C$ of online Appendix B. The strategy of the proof is to write shifts in $\sigma_{s}$ as a combination of composition and extension effects. The term $e^{\Delta \mu} \sigma_{s}\left(\sigma_{s}-\sigma_{c}\right)\left(\bar{s}-\mu_{s}\right)$ accounts for the extension effects. They are equivalent to a rise in $\mu_{s}$ : an increase in $\sigma_{s}$ implies that human capital is added to the upper tail whereas it is removed from the lower tail. This is equal to an upward shift in $\mu_{s}$. The extension effect of a decrease in $\sigma_{s}$ therefore leads to an increase in wage dispersion. The intuition is that a decrease in $\sigma_{s}$ reduces supply in both tails of the skill distribution by the same amount, measured in physical terms. However, in value terms, the effect on the upper tail is more substantial, since wages are higher in the upper tail. Hence, where the direct effect of the decrease in the dispersion of the human capital distribution leads to wage compression, the extension part of the general equilibrium effect leads to an increase in wage dispersion. When wage compression is the policy goal, a compression of the human capital distribution might therefore be counterproductive. This reinforces the conclusions of Heckman et al. (1998a, 1998b): trying to support the skill groups in the lower tail of the skill distribution by a schooling program might very well have perverse effects. The complexity dispersion parameter is no 
longer independent of $s$ when $\sigma_{s} \neq \sigma_{c}$. When $\sigma_{s}>\sigma_{c}$, the complexity dispersion parameter becomes upward sloping, and vice versa.

Figure 4 offers a graphical representation of propositions 5 and 6 . Figure $4 a$ considers the change in the wage schedule due to an increase $d \mu_{s}$ in the mean of the skill distribution for the case of a linear wage locus, $\sigma_{s}=\sigma_{c}$. The continuous line represents the initial locus of log wages, $\bar{w}\left(\bar{s} ; \mu_{s}, \sigma_{c}\right)$, and the dotted line the locus after the increase in $\mu_{s}, \bar{w}\left(\bar{s} ; \mu_{s}+d \mu_{s}, \sigma_{c}\right)$. The increase in $\mu_{s}$ reduces the return to human capital, $\bar{w}^{\prime}\left(\bar{s} ; \mu_{s}, \sigma_{c}\right)$. An increase in the first moment of the skill distribution has a direct positive effect on the first moment of the log wage distribution but a negative general equilibrium effect on its second moment. Since substitution effects sum to zero, some workers gain and some lose. The break-even point can be calculated from proposition 5 by solving the condition $d \bar{w}\left(\bar{s} ; \mu_{s}, \sigma_{s}\right) / d \mu_{s}=0$ for $\bar{s}$. This yields $\bar{s}=$ $\mu_{s}+\sigma_{s}^{2}$. In figure $4 a$, this is the point at which the continuous and the dotted lines cross each other.

Figure $4 b$ considers the change in the wage schedule due to a change in $\sigma_{s}$ for $\Delta \mu=0$ and $\sigma_{c}=1$, starting from the special case of a linear wage function, $\sigma_{s}=\sigma_{c}$. I calculated both the exact solution (dotted lines) and the Taylor approximation derived from proposition 5 (continuous lines) for $\sigma_{s}$ ranging from 0.9 to 1.1 in the first panel and from 0.8 to 1.2 in the second panel. For $\sigma_{s}>\sigma_{c}$, the wage function becomes concave: the supply of both high- and low-skilled workers goes up, at the expense of the supply of medium-skilled workers, and vice versa for $\sigma_{s}<\sigma_{c}$. Hence, the wages for both high- and low-skilled workers go down, to the benefit of the medium-skilled workers, yielding a wage distribution that is skewed to the left. An increase in the second moment of the skill distribution therefore has a negative general equilibrium effect on the third moment of the wage distribution. My Taylor expansion is highly accurate for $\sigma_{s}>\sigma_{c}$. The reason is that wages are relatively low in the tails of the distribution in that case, so that these tails, where the approximation is necessarily less precise, carry less weight in the value distribution. For $\sigma_{s}<\sigma_{c}$, the expansion is far less precise. However, the benchmark parameters for the calculations, $\Delta \mu=0$ and $\sigma_{c}=1$, imply a larger variance of $\log$ wages, $\mathrm{V}[w]=1$, than is observed empirically. This makes the expansion less precise.

Katz and Murphy's (1992) evidence on the U.S. labor market history is consistent with a value of the elasticity of substitution between lowand high-skilled workers equal to 1.4. As explained in Section III.A, elasticities of substitution are not a very useful concept in this type of DIDES world, since their magnitude strongly depends on the coarseness of the classification of skill groups. However, the variation in Katz and Murphy's data is mainly due to the increase in the average level of human capital. In my model, that variation is equivalent to an increase 
a

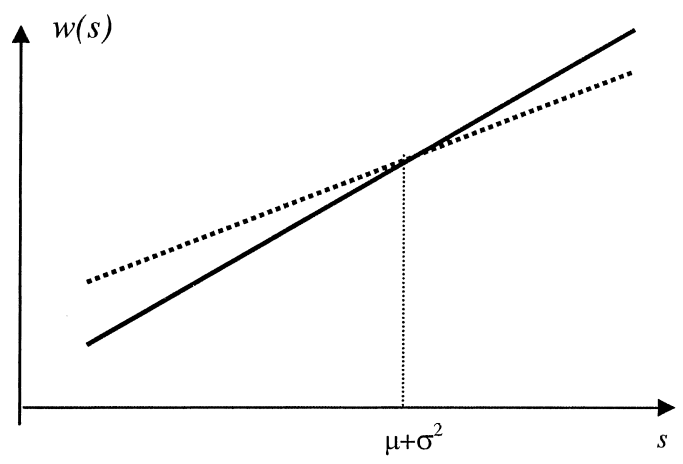

b
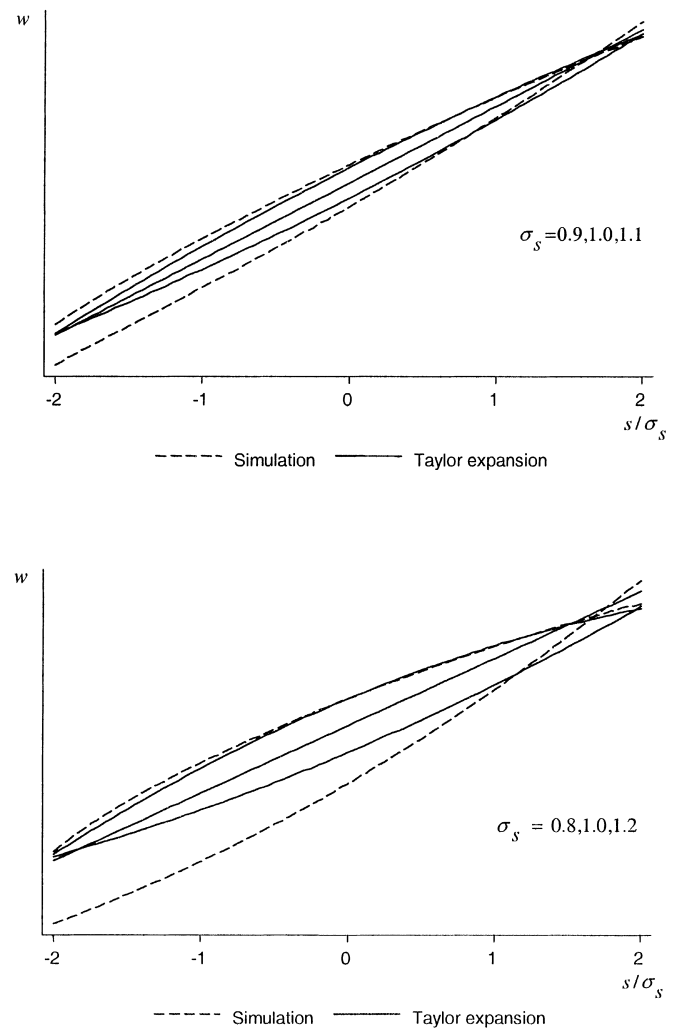

FIg. 4.-Relative wage effects of shifts in the skill distribution. $a$, A shift in the linear case. $b$, A shift in $\sigma$. 
in $\mu_{s}$. For the special case $\sigma_{s}=\sigma_{c}$, one can derive a relation between Katz and Murphy's estimate of the elasticity of substitution in a model with two skill groups and the complexity dispersion parameter or compression elasticity.

Proposition 7. Consider the model laid out in this section, in particular the special case $\sigma_{s}=\sigma_{c}$. Let there be variation in $\bar{w}^{\prime}\left(\bar{s} ; \mu_{s}, \sigma_{c}\right)$ due to shifts in the mean of the skill distribution, $\mu_{s}$. Suppose that a researcher uses Katz and Murphy's (1992) two-type framework, and let $\bar{s}^{*}$ be the borderline between two broadly defined skill categories: all workers for whom $\bar{s}<\bar{s}^{*}$ are classified as low-skilled and all $\bar{s}>\bar{s}^{*}$ are classified as high-skilled. Then the elasticity of substitution between lowand high-skilled workers, $\eta_{\text {low-high }}$, will be estimated as

$$
\eta_{\text {low-high }}=-\frac{\gamma}{\sigma_{s}^{2}}=-\frac{1}{\gamma \mathrm{V}[w]},
$$

where $\mathrm{V}[w]$ denotes the variance of $\log$ wages.

See Section $D$ in online Appendix B for a proof. Since the variance of $\log$ wages $\mathrm{V}[w] \cong 0.36$ for the United States, $\gamma=1 /(1.4 \mathrm{~V}[w]) \cong 2$. This number is perfectly in line with the results by Teulings and van Rens (2002).

\section{Some Final Remarks}

The comparative advantage in production technology has been shown to imply the distance-dependent elasticity of substitution structure, where the substitutability between types declines with their distance in terms of their skill level. For many applications, this structure is more realistic than, for example, Dixit and Stiglitz's (1977) continuous-type CES production function, where all inputs are equally substitutable. Moreover, where the substitution process in the CES function is a black box, the DIDES model is based on an explicit assignment model. The comparative advantage framework links the theory of substitution to assignment models (see Sattinger 1993).

General shifts in the distribution of human capital do not provide a good testing ground of the implications of the DIDES framework, for example, vis-à-vis the Dixit and Stiglitz CES function. The reason is that the peaked patterns of complementarity depicted in figure 2 tend to cancel out when the skill distribution is shifted simultaneously for many skill groups. The ideal experiment is an increase in minimum wages. This policy experiment deletes the least skilled workers from employment and therefore has a clearly defined impact on the skill distribution. Moreover, deleting the lowest- or the highest-skilled group has the most pronounced effect on relative wages (see fig. 1). The DIDES framework 
predicts substantial spillover effects of the increase in the minimum wage to higher wage levels, since firms switch their labor demand to the closest substitutes for the least skilled workers who are thrown out of employment. Teulings (2003) offers empirical evidence for these spillover effects.

The results on the acquisition of additional human capital have important positive and normative implications for economic policy. They point to a set of both positive and negative externalities of the schooling decision of one skill type to the value of human capital of other skill types. A type $s$ worker who has to decide on the investment in capital takes wages $w(s)$ as given. She will set the return to an additional unit of skill, $w^{\prime}(s)$, equal to the cost of acquiring that human capital. She does not take into account that her decision has a general equilibrium effect that affects the wage function $w(s)$ as such. The composition effect yields the unambiguous prediction that workers skilled less than $s$ gain since their wages go up, whereas workers skilled better than $s$ lose (the predictions regarding the extension effect are more ambiguous). Obviously, these positive and negative externalities evaluated at their monetary value cancel, since the value-weighted sum of substitution effects equals zero in a constant returns to scale world, as considered in the paper. However, the political process might attach different weights to the value of various citizens. A median-voter model in which the mean income exceeds the median is a typical example. On the positive side, these externalities might explain why many democracies subsidize higher education; see Dur and Teulings (2004) for a formal analysis. On the normative side, there are implications for the targeting of training programs for the relief of the low-skilled. It might not be optimal to target these programs tightly to the left tail of the skill distribution in order to improve the position of the least skilled workers. Such targeting might be counterproductive, by both the composition and the extension effects: the additional human capital depresses their wages. Training policies can be better geared toward higher skill levels to let the least skilled benefit from the general equilibrium effects.

\section{Appendix A}

\section{A. Proof of Proposition 1}

The proof is an extension of arguments provided in Teulings (1995). Hence, I provide a heuristic proof only. Weak inequality versions of parts 2 and 4 can be 
proved from the definition of $c_{i}$ (see eq. [2]): ${ }^{10}$

$$
\begin{aligned}
s_{i} c_{i}-w_{i} & =s_{i-1} c_{i}-w_{i-1} \geq s_{i-2} c_{i}-w_{i-2} \Rightarrow \\
0 & =c_{i} \Delta s-\Delta w_{i} \geq-c_{i} \Delta s+\Delta w_{i-1}=-\Delta w_{i}+\Delta w_{i-1} \Rightarrow \\
\Delta^{2} w_{i} & \geq 0 .
\end{aligned}
$$

In the second line, I substract $s_{i} c_{i-1}-w_{i-1}$ from the first line. This proves part 4. Equation (2) implies

$$
\Delta c_{i} \Delta s=\Delta^{2} w \geq 0
$$

proving part 2 since $\Delta s>0$. The proof of the strict inequality of these parts of the proposition uses the shapes of the Leontief coefficients $\exp [-\delta(c)]$ and of labor supply exp $[-\chi(s)]$, which are both bounded and strictly positive by part 3 of assumption A. Equality would imply $\Delta c_{i}=0$ or $c_{i}=c_{i+1}$ : several skill types would be employed in the same task. This would require either mass points in task demand or holes in the distribution of skill supply. Since these are ruled out by assumption, strict inequality applies. Part 3 follows immediately from equation (2), since both $c_{i}$ and $\Delta s$ are strictly positive. Parts 5 and 6 follow from a limiting argument regarding parts 3 and 4, where part 6 makes sure that the least skilled worker is employed in the least complex task and the best in the most complex. QED

\section{B. Proof of Proposition 2}

The vector of first derivatives of log cost function (5) is

$$
\begin{aligned}
\underline{p}_{w_{i}}(\underline{w})= & \frac{1}{P(\underline{w})} \int_{c_{i}}^{c_{i+1}} \exp \left[\delta(c)+w_{i}-s_{i} c\right] d c+\frac{1}{P(\underline{w}) \Delta s} \\
& \times\left\{\exp \left[\delta\left(c_{i}\right)+w_{i-1}-s_{i-1} c_{i}\right]-\exp \left[\delta\left(c_{i}\right)+w_{i}-s_{i} c_{i}\right]\right. \\
& \left.+\exp \left[\delta\left(c_{i+1}\right)+w_{i+1}-s_{i+1} c_{i+1}\right]-\exp \left[\delta\left(c_{i+1}\right)+w_{i}-s_{i} c_{i+1}\right]\right\},
\end{aligned}
$$

where $P(\underline{w}) \equiv \exp [p(\underline{w})]$, and the arguments of $c\left(w_{i-1}, w_{i}\right)$ are omitted for notational convenience. The first term measures the effect of a change in $w_{i}$ on the $\log$ cost per unit of output. The second term measures the effects via the change in the boundaries of integration $c_{i}$ and $c_{i+1}$. The latter terms cancel because of the envelope theorem (see eq. [4]). The first derivative of the log cost function with respect to $w_{i}$ is equal to the value share of type $i$ (see Sec. $A$ of App. B in the online edition). Omitting the vanishing terms yields

$$
v_{i}=\frac{1}{P(\underline{w})} \int_{c_{i}}^{c_{i+1}} \exp \left[\delta(c)+w_{i}-s_{i} c\right] d c,
$$

\footnotetext{
${ }^{10}$ The proof of part 1 of proposition 1 is essentially a generalization of this argument, showing that if a type $c$ firm is indifferent between employing a type $i$ and a type $j, j>i$, then it is indifferent between employing any worker type in $[i, j]$, and hence, it is indifferent between type $i$ and type $i+1$. Hence, there exists a job type $c$ that is indifferent between types $i$ and $i+1$ and that weakly prefers these types above all other types.
} 
where $v_{i}$ is the value share of worker type $i$. By equations (A2) and (3) we have

$$
\begin{aligned}
\lim _{\Delta s \rightarrow 0} \frac{v_{i}}{\Delta s} & =\frac{1}{P(\underline{w})} \exp \left[\delta\left(c_{i}\right)+w_{i}-s_{i} c_{i}\right] \lim _{\Delta s \rightarrow 0} \frac{\Delta c_{i+1}}{\Delta s} \\
& =\frac{w^{\prime \prime}\left(s_{i}\right)}{P(\underline{w})} \exp \left[\delta\left(c_{i}\right)+w_{i}-s_{i} c_{i}\right] \equiv v\left(s_{i}\right) .
\end{aligned}
$$

In the first step, the value of the integral is approximated by the value of the integrand times the width of the integration interval. The second step uses equation (3).

For the second derivatives, three cases can be distinguished. First, the second derivatives of the elements are not adjacent to the main diagonal:

$$
\begin{aligned}
p_{w_{i} w_{j}}(\underline{w})_{\mid j \neq i-1, i, i+1}= & -\frac{1}{P(\underline{w})^{2}} \int_{c_{i}}^{c_{i+1}} \exp \left[\delta(c)+w_{i}-s_{i} c\right] d c \\
& \times \int_{c_{j}}^{c_{j+1}} \exp \left[\delta(c)+w_{j}-s_{j} c\right] d c \\
= & -v_{i} v_{j} .
\end{aligned}
$$

The terms referring to the change in the allocation of workers to tasks cancel because neither $c_{i}$ and $c_{i+1}$ nor $c_{j}$ and $c_{j+1}$ depend on both $w_{i}$ and $w_{j}$. Hence, only the direct effect of $w_{i}$ and $w_{j}$ remains. The final equality follows from (A2). Second, the second derivatives of the elements adjacent to the main diagonal satisfy

$$
\begin{aligned}
p_{w_{i} w_{i-1}}(\underline{w}) & =-v_{i} v_{i-1}+\frac{1}{P(\underline{w}) \Delta s} \exp \left[\delta\left(c_{i}\right)+w_{i}-s_{i} c_{i}\right] \\
& =-v_{i} v_{i-1}+\frac{v\left(s_{i}\right)}{w^{\prime \prime}\left(s_{i}\right) \Delta s}
\end{aligned}
$$

where equation (A3) is applied for the second step. Here, the allocation of workers to tasks does matter, since $c_{i}$ depends on both $w_{i}$ and $w_{i-1}$. Finally, the second derivatives of the elements on the main diagonal are determined as residual items, from $\mathbf{H} \underline{V}=\underline{0}$, where $\underline{V}$ is a vector of value shares and $\underline{0}$ is a vector of zeros. QED

\section{Proof of Proposition 3}

Define $\mathbf{G}^{+} \equiv \mathbf{H}^{+^{-1}}$. Hence

$$
e_{i j} \equiv e\left(s_{i}, s_{j}\right)=\frac{g_{i j}}{v_{i} v_{j}} .
$$

Define $g\left(s_{i}, s_{j}\right)=\lim _{\Delta s \rightarrow 0}\left(g_{i j} / \Delta s^{2}\right)$. Then, by equation (A3),

$$
\lim _{\Delta s \rightarrow 0} \frac{g_{i j}}{v_{i} v_{j}}=\frac{g\left(s_{i}, s_{j}\right)}{v\left(s_{i}\right) v\left(s_{j}\right)} \equiv e\left(s_{i}, s_{j}\right) .
$$

The function $g(\cdot)$ will be characterized by a second-order differential equation in its first argument, keeping the second argument constant. This differential 
equation is derived in three steps. First, $\mathbf{G}^{+} \equiv\left\{g_{i j}\right\}$ is characterized. Second, the differential equation for $g(\cdot)$ is derived by letting $\lim \Delta s \rightarrow 0$. Third, the differential equation is solved using appropriate initial conditions.

LEMma 1. Characterization of $\mathbf{G}^{+}$. Let $g_{i}$ and $\underline{h}_{i}$ denote the $i$ th vectors of $\mathbf{G}^{+}$ and $\mathbf{H}^{+}$, respectively. Then

1. $g_{j}^{\prime} \underline{h}_{I+1}=0 \Rightarrow \sum_{i=1}^{I} g_{i j}=0$ (since $\left.h_{I+1, I+1}=0\right)$;

2. $\quad g_{j}^{\prime} \underline{h}_{i}=0, i \neq 1, j, I, I+1 \Rightarrow h_{i-1, i} g_{i-1, j}-2 q_{i} g_{i j}+h_{i+1, i} g_{i+1, j}+v_{j}=0$;

3. $\quad g_{i}^{\prime} \underline{h}_{i}=1, i \neq 1, I, I+1 \Rightarrow h_{i-1, i} g_{i-1, i}-2 q_{i} g_{i i}+h_{i+1, i} g_{i+1, i}+v_{i}=1$; and

4. $g_{j}^{\prime} \underline{h}_{1}=0, j \neq 1, I+1 \Rightarrow-\left(v_{2} / v_{1}\right) h_{21} g_{1 j}+h_{21} g_{2 j}+v_{j}=0$, where

$$
q_{i} \equiv \frac{1}{2}\left(\frac{v_{i-1}}{v_{i}} h_{i-1, i}+\frac{v_{i+1}}{v_{i}} h_{i+1, i}\right)
$$

Proof. Lemma 1 follows from the definition of $\mathbf{H}^{+}$, proposition 1 , and the identity $\mathbf{G}^{+} \mathbf{H}^{+}=\mathbf{I}$. From there, it is easy to see that $g_{I+1}=[\underline{v} \mid 0]$, since $\mathbf{H}^{+}[\underline{v} \mid 0]=[\underline{0} \mid 1]$, part 1. The other parts follow from similar arguments. QED

Lemma 2. Characterization of $g\left(s_{i}, s_{j}\right)$. For any $s_{j}, s_{j} \in\left[s^{-}, s^{+}\right]$, the function $g\left(s_{i}, s_{j}\right)$ is fully characterized as follows:

1. $g\left(s_{i}, s_{j}\right)=g\left(s_{j}, s_{i}\right)$

2. the function $g\left(s_{i}, s_{j}\right)$, with $s_{j}$ constant, is continuous but nondifferentiable at $g\left(s_{j}, s_{j}\right)$;

3. apart from this nondifferentiability, this function satisfies the differential equation

$$
\begin{aligned}
g_{11}\left(s_{i}, s_{j}\right)= & {\left[\frac{v^{\prime}\left(s_{i}\right)}{v\left(s_{i}\right)}+\frac{w^{\prime \prime \prime}\left(s_{i}\right)}{w^{\prime \prime}\left(s_{i}\right)}\right] g_{1}\left(s_{i}, s_{j}\right) } \\
& -\left[\frac{v^{\prime}\left(s_{i}\right) w^{\prime \prime \prime}\left(s_{i}\right)}{v\left(s_{i}\right) w^{\prime \prime}\left(s_{i}\right)}-\frac{v\left(s_{i}\right) v^{\prime \prime}\left(s_{i}\right)-v^{\prime}\left(s_{i}\right)^{2}}{v\left(s_{i}\right)^{2}}\right] g\left(s_{i}, s_{j}\right) \\
& -w^{\prime \prime}\left(s_{i}\right) v\left(s_{i}\right) v\left(s_{i}\right) g\left(s_{i}, s_{j}\right)
\end{aligned}
$$

4. its first derivatives at the boundaries of its domain satisfy

$$
g_{1}\left(s^{-}, s_{j}\right)=\frac{v^{\prime}\left(s^{-}\right)}{v\left(s^{-}\right)} g\left(s^{-}, s_{j}\right)
$$

and a similar equation for $s^{+}$; and

5. $\int_{s^{-}}^{s^{+}} g\left(s, s_{j}\right) d s=0$.

Proof. The proof of part 1 of lemma 2 follows from the symmetry of $\mathbf{H}^{+}$. For the other parts, define the difference operators with respect to the first index of $g_{i j}: \Delta g_{i j}=g_{i j}-g_{i-1, j}$ and $\Delta^{2} g_{i j}=g_{i j}-2 g_{i-1, j}+g_{i-2, j}$. Then part 2 of lemma 1 can be written as

$$
\begin{aligned}
0= & q_{i} \Delta^{2} g_{i+1, j}+\left(q_{i}-h_{i-1, i}\right) g_{i-1, j}+\left(h_{i+1, i}-q_{i}\right) g_{i+1, j} \\
& +\left(h_{i-1, i}-2 q_{i}+h_{i+1, i}\right) g_{i j} .
\end{aligned}
$$


Since $\lim _{\Delta s \rightarrow 0}\left(g_{i j} / \Delta s^{2}\right)=g\left(s_{i}, s_{j}\right)$,

$$
\begin{aligned}
\lim _{\Delta s \rightarrow 0} \frac{\Delta g_{i j}}{\Delta s^{3}} & =g_{1}\left(s_{i}, s_{j}\right), \\
\lim _{\Delta s \rightarrow 0} \frac{\Delta^{2} g_{i j}}{\Delta s^{4}} & =g_{11}\left(s_{i}, s_{j}\right), \\
\lim _{\Delta s \rightarrow 0} h_{i} \Delta s^{3} & =\lim _{\Delta s \rightarrow 0} q_{i} \Delta s^{3}=\frac{1}{v\left(s_{i}\right) w^{\prime \prime}\left(s_{i}\right)}, \\
\lim _{\Delta s \rightarrow 0}\left(q_{i}-h_{i-1, i}\right) \Delta s^{2} & =\frac{1}{2} \frac{1}{v\left(s_{i}\right) w^{\prime \prime}\left(s_{i}\right)}\left[\frac{v^{\prime}(s)}{v(s)}+\frac{w^{\prime \prime \prime}(s)}{w w^{\prime \prime}(s)}\right], \\
\lim _{\Delta s \rightarrow 0}\left(h_{i-1, i}-2 q_{i}+h_{i+1, i}\right) \Delta s & =\frac{1}{v\left(s_{i}\right) w^{\prime \prime}\left(s_{i}\right)}\left[\frac{v^{\prime}(s) w^{\prime \prime \prime}(s)}{v(s) w^{\prime \prime}(s)}-\frac{v(s) v^{\prime \prime}(s)-v^{\prime}(s)^{2}}{v(s)^{2}}\right] .
\end{aligned}
$$

Multiplying equation (A7) by $\Delta s$ and applying the above relations yields part 3 . When

$$
\lim _{\Delta s \rightarrow 0} \frac{\Delta g_{i j}}{\Delta s^{3}} \neq \lim _{\Delta s \rightarrow 0} \frac{\Delta g_{i+1, j}}{\Delta s^{3}},
$$

then define

$$
\begin{aligned}
\lim _{\Delta s \rightarrow 0} \frac{\Delta g_{i j}}{\Delta s^{3}} & =g_{1 \uparrow}\left(s_{i}, s_{j}\right), \\
\lim _{\Delta s \rightarrow 0} \frac{\Delta g_{i+1, j}}{\Delta s^{3}} & =g_{1 \downarrow}\left(s_{i}, s_{j}\right),
\end{aligned}
$$

where the arrows denote the left and right partial derivatives of $g(\cdot)$, respectively. Hence, part 3 of lemma 1 implies

$$
\frac{1}{v\left(s_{i}\right) w^{\prime \prime}\left(s_{i}\right)}\left[g_{1 \uparrow}\left(s_{i}, s_{j}\right)+g_{1 \downarrow}\left(s_{i}, s_{j}\right)\right]=1 .
$$

Therefore, $g\left(s, s_{j}\right)$ is continuous but nondifferentiable at $s=s_{j}$, proving part 2 . The limit for $\Delta s \rightarrow 0$ of part 4 of lemma 1 yields part 4 of lemma 2. A similar equation applies for $s=s^{+}$. Finally, the limit of part 1 of lemma 1 yields part 5 of lemma 2. QED

The final step links proposition 3 to lemma 2. Let us work backward: $g\left(s_{i}, s_{j}\right)$ can be calculated from proposition 3 by multiplying both sides by $v\left(s_{i}\right) v\left(s_{j}\right)$, equation (A6). Part 3 of lemma 2 can be recovered from there by dividing by $v\left(s_{i}\right)$, differentiating once, multiplying the result by $v\left(s_{i}\right) / w^{\prime \prime}\left(s_{i}\right)$, differentiating a second time, and multiplying the result by $w^{\prime \prime}\left(s_{i}\right)$. The four initial conditions are satisfied. The equality of $g\left(s_{i}, s_{j}\right)$ for $s_{i}=s_{j}$ for both branches of the locus follows from the symmetry of proposition 3 . The initial condition for the first differential equation for $s=s^{-}$, part 4 of lemma 2, is satisfied because the derivative of the first term in proposition 3 vanishes since $V\left(s^{-}\right)=0$. Likewise, the initial condition for $s^{+}$is satisfied since $V\left(s^{+}\right)=1$. Part 5 of lemma 2 can be checked by first evaluating it for $s_{j}=s^{+}$. Then $s_{i}<s_{j}$ for the full support of $s_{i}$, and hence, we have to apply only the equation for $s_{i}<s_{j}$ and not its symmetric counterpart for $s_{i}>s_{j}$. The second term drops out. It then follows immediately 
that part 5 of lemma 2 is satisfied. Next, the equation has to be verified for $s_{j}<s^{+}$. Since part 5 of lemma 2 applies identically for all $s_{j}$, it can be differentiated with respect to $s_{j}$. Substitution of part 4 of lemma 2 yields

$$
\begin{aligned}
\int_{s^{-}}^{s^{+}} g_{2}\left(s, s_{j}\right) d s= & \frac{v^{\prime}\left(s_{j}\right)}{v\left(s_{j}\right)} \int_{s^{-}}^{s^{+}} g\left(s, s_{j}\right) d s \\
& -w^{\prime \prime}\left(s_{j}\right)\left[1-V\left(s_{j}\right)\right] \int_{s^{-}}^{s_{j}} v(s) d s+w^{\prime \prime}\left(s_{j}\right) V\left(s_{j}\right) \int_{s^{-}}^{s_{j}} v(s) d s .
\end{aligned}
$$

The first term accounts for the derivative of the factor $v\left(s_{j}\right)$, which comes in as a result of the transfer from $e(\cdot)$ to $g(\cdot)$. The second term accounts for the derivative of $e_{2}\left(s_{i}, s_{j}\right)$ for $s_{i}<s_{j}$ and the third term for $s_{i}>s_{j}$. The second and third terms cancel. The first term vanishes when part 5 of lemma 2 is satisfied. Since part 5 is satisfied for $s_{j}=s^{+}$, by induction it will also be satisfied for $s_{j}<s^{+}$. QED

\section{References}

Diewert, W. E. 1971. “An Application of the Shephard Duality Theorem: A Generalized Leontief Production Function.” J.P.E. 79 (May/June): 481-507.

Dixit, Avinash K., and Joseph E. Stiglitz. 1977. "Monopolistic Competition and Optimum Product Diversity." A.E.R. 67 (June): 297-308.

Dur, Robert J., and Coen N. Teulings. 2004. "Are Education Subsidies an Efficient Redistributive Device?” In Labor Market Institutions and Public Regulation, edited by Jonas Agell, Michael Keen, and Alfons J. Weichenrieder. Cambridge, MA: MIT Press.

Heckman, James J., Lance Lochner, and Christopher Taber. 1998a. "Explaining Rising Wage Inequality: Explorations with a Dynamic General Equilibrium Model of Labor Earnings with Heterogeneous Agents.” Working Paper no. 6384 (January), NBER, Cambridge, MA.

. 1998b. "General Equilibrium Treatment Effects: A Study of Tuition Policy.” Working Paper no. 6426 (February), NBER, Cambridge, MA.

Heckman, James J., and Guilherme Sedlacek. 1985. "Heterogeneity, Aggregation, and Market Wage Functions: An Empirical Model of Self-Selection in the Labor Market." J.P.E. 93 (December): 1075-1125.

Juhn, Chinhui, Kevin M. Murphy, and Brooks Pierce. 1993. "Wage Inequality and the Rise in Returns to Skill." J.P.E. 101 (June): 410-42.

Katz, Lawrence F., and Kevin M. Murphy. 1992. "Changes in Relative Wages, 1963-1987: Supply and Demand Factors.” Q.J.E. 107 (February): 35-78.

Layard, Richard, and Alan A. Walters. 1978. Microeconomic Theory. New York: McGraw-Hill.

Rosen, Sherwin. 1974. "Hedonic Prices and Implicit Markets: Product Differentiation in Pure Competition.” J.P.E. 82 (January/February): 34-55.

Sattinger, Michael. 1975. "Comparative Advantage and the Distributions of Earnings and Abilities." Econometrica 43 (May): 455-68.

. 1993. "Assignment Models of the Distribution of Earnings." J. Econ. Literature 31 (June): 831-80.

Teulings, Coen N. 1995. "The Wage Distribution in a Model of the Assignment of Skills to Jobs.” J.P.E. 103 (April): 280-315.

- 2000. "Aggregation Bias in Elasticities of Substitution and the Minimum Wage Paradox.” Internat. Econ. Rev. 41 (May): 359-98. 
2003. "The Contribution of Minimum Wages to Increasing Wage Inequality." Econ. J. 113 (October): 801-33.

Teulings, Coen N., and Pieter A. Gautier. 2004. "The Right Man for the Job." Rev. Econ. Studies 71 (April): 553-80.

Teulings, Coen N., and Thijs van Rens. 2002. "Education, Growth and Income Inequality." Discussion Paper no. 02-001/3, Tinbergen Inst., Amsterdam/ Rotterdam.

Tinbergen, Jan. 1956. "On the Theory of Income Distribution." Weltwirtshaftliches Archiv 77 (2): 155-73. 